\title{
Deposition Mechanism Analysis of Cold Sprayed Fluoropolymer Coatings and Its Wettability Evaluation
}

Wesley Lock Sulen ${ }^{1, *}$, Kesavan Ravi ${ }^{1,2, \dagger}$, Chrystelle Bernard ${ }^{1,2,3}$, Yuji Ichikawa ${ }^{1}$, Kazuhiro Ogawa $^{1,2}$

${ }^{1}$ Fracture and Reliability Research Institute, Tohoku University, Japan

${ }^{2}$ ELyTMaX UMI 3757, CNRS - Université de Lyon - Tohoku University, International Joint Unit, Tohoku University, Sendai, Japan

${ }^{3}$ Frontier Research Institute for Interdisciplinary Sciences, Tohoku University, Japan

${ }^{\dagger}$ Present address: Indian Institute of Technology (Indian School of Mines) Dhanbad, India

*Corresponding author (email: wesley.locksulen@,rift.mech.tohoku.ac.jp)

\begin{abstract}
Polymer coating by cold-spray presents interesting features such as the possibility to protect metallic substrates or to add functionalities to a structure. However, it is characterized by a low deposition efficiency and a weak interface between the substrate and the coating. In this study, we performed fluoropolymer coatings by the cold-spray process. Analysis of the particle deposition during cold-spray highlighted the importance of the particle size, substrate temperature, and inlet gas temperature and pressure on the adhesion polymer/substrate. The addition of hydrophobized fumed nano-ceramics (FNC) to the polymer feedstock enhances the deposition efficiency and polymer adhesion on the substrate. The addition of fumed nanoalumina (FNA) to the polymer feedstock tends to give better results than fumed nano-silica in terms of deposition efficiency thanks to (i) the difference of surface charge leading to the attractive force between the polymer and the FNA during the powder preparation stage, and (ii) a homogeneous repartition of the FNA on the polymer particle surface. In addition, the hydrophobization of the FNC maintains and enhances the hydrophobicity and water repellency properties of the fluoropolymer coating.
\end{abstract}


Keywords: Hydrophobic coating; Cold spray; Polymer powder, Nano-ceramic particles; Fluoropolymer

\section{Introduction}

Fluoropolymers, like fluoroethylene propylene (FEP), polytetrafluoroethylene (PTFE) or Teflon, are known for their low-friction surface, high corrosion and chemical resistance due to their strong carbon-carbon backbone and carbon-fluorine group structure (Ref $1-3)$. The fluorine on a fluoropolymer repels other molecules so well that it is difficult for any material to adhere to its surface ( $\operatorname{Ref} 4)$. FEP is a thermoplastic polymer exhibiting a semi-crystalline microstructure, characterized by a degree of crystallinity lower than a PTFE (Ref 3). Due to a melting temperature in the range of $275^{\circ} \mathrm{C}$ to $310^{\circ} \mathrm{C}$ (Ref 5) and highly inert, FEP can withstand high operating temperature and any extreme chemical abusive environments. However, a pure FEP coating with strong adhesion is challenging to manufacture due to its low surface energy which results in a weak interfacial adhesion (Ref 6). Hence, surface treatment techniques are required to obtain a substantial increase in interfacial adhesion, primarily using plasma or a primer coat. The plasma treatment allows interfacial adhesion without chemical structure modification on a fluoropolymer surface, whereas a primer coat allows chemical modification to facilitate adhesion/bonding with other materials (Ref 7). In other words, the process to adhere a fluoropolymer to other material or vice-versa is not an easy process-time consuming and involving additional cost. Furthermore, the chemicals used for the primer are reactive and not environmentally friendly and can be harmful, which is known to be the stumbling blocks for this material. On the same note, adhesion of FEP by solid-state deposition spray process, such as cold-spray, is an attractive alternative due to low cost, environmentally-friendly aspect, and fast process. 
In the cold-spray process, nano to micro-sized particles, known as feedstock powder, are accelerated by the gas velocity in the range of supersonic speed before impacting the substrate surface (Ref 8-14). Compared to thermal spray which requires molten or semi-molten droplets to splat on the target surface and cool down to form layered deposits, deposits from the coldspray process or solid-state deposition are more dense and low in porosity (Ref 15,16$)$. Since the discovery of the cold-spray in the 1980s, studies have been carried out extensively using metallic particles on metallic substrates (Ref 17-19). Recently, interests in the polymeric materials deposition by cold-spray has increased significantly (Ref 20-30), mainly driven by their light-weight, corrosion resistance and wear resistance properties. However, the deposition efficiency of these materials remains low because of their viscoelastic behavior enhanced by the material temperature.

The deposition of thermoplastic polyolefin, with a mean size of 150 to $250 \mu \mathrm{m}$, on a polyethylene sheet and aluminum sheet substrates, was studied by Xu et al. (Ref 20). They have successfully demonstrated fully dense thermoplastic deposits on the polyethylene substrate. Contrary to the polyethylene substrate, the formation of polyolefin deposits on the aluminum substrate only occurred after a thin layer of melted thermoplastic had been formed. Despite this, the low deposition efficiency in the range of 5\% was observed in the spray results, possibly caused by erosion on the deposited polymer during cold spraying when the cohesion and adhesion at the interface were comparatively weak.

To enhance the adhesion between the powder and substrate and increase the deposition efficiency, identification of the key parameters, related to cold-spray process, is primordial. Thus, on high-density polyethylene (HDPE), Bush et al. (Ref 25) optimized the stand-off distance, particles size, substrate temperature, and particle impact velocity to achieve higher deposition efficiency. The combination of computational and experimental studies allow them to design a new cold-spray system and to obtain deposition efficiency close to $10 \%$. 
Ravi et al. (Ref $23,24,27)$ have successfully demonstrated a $4 \mathrm{~mm}$ thickness of $60 \mu \mathrm{m}$ of mean sized ultra-high molecular weight polyethylene (UHMWPE) through nano-ceramic addition in the feedstock powder and a modified nozzle length. Fumed nano-alumina was considered to work in the coating build-up by creating a network of finely dispersed particles that led to the increase in thickness for the thermoplastic polymer. The hydroxyl group on the fumed nanoalumina particle works as a bridge between the nano-particles and UHMWPE particles. Compared to a metallic coating, polymer coating by cold-spray uses lower gas pressure and temperature (Ref 31$)$. To soften the particle and enhance its bonding capabilities with the substrate, increasing the surface temperature of the particles are needed. This can be achieved by increasing the resident time of the particles inside the nozzle, and therefore increasing the length of the nozzle as proposed by Ravi et al. (Ref 23,24,27). Furthermore, by studying the cold-spraying of various thermoplastic polymers on a series of polymer substrates, Khalkhali et al. (Ref 22) found that cold-sprayed polymers samples exhibit material properties equivalent to melt-casted samples in terms of ultimate tensile strength and Young's modulus. Polyurethane, polystyrene, polyamide-12, HDPE, and UHMWPE with a mean size of 20 to $50 \mu \mathrm{m}$ were deposited on similar material in which highest deposition efficiency of $8.4 \%$ was obtained for HDPE on low-density polyethylene. They also highlighted the importance of the tilted angle of the substrate during cold-spray in which deposition efficiency decreased with increasing tilted angle.

Studies on the deposition behaviour of reinforced or specifically structured polymers were carried out by others. Gillet et al. (Ref 32) used copper particles on Poly-Ether-Ether-Ketone (PEEK) layered carbon fibre reinforced plastic (CFRP) to enable deposition and avoid erosion of the composite substrate. They discovered that a thin layer of pure PEEK on the composite CFRP substrate was important to facilitate the deposition via particle penetration into the thin layer. Meanwhile, Yang et al. (Ref 33) highlighted the effect of particles glass transition 
temperature on their deposition behaviour during cold-spray. For polymers, the glass transition temperature is of high importance since it corresponds to a change of mechanical behaviour and mechanical properties of the amorphous chains (Ref 34,35). It marks the transition between glassy to rubbery states; to elastic-viscoplastic behaviour to highly viscoelastic-viscoplastic behaviour.

Recent works regarding polymeric particle cold-spray are driven by the time and cost reduction it offers, which is an advantage for additive manufacturing (Ref 22,36) and functional coating fabrication (Ref 28,37). For polymers exhibiting non-adhesive properties, like fluoropolymers, additive manufacturing seems particularly suitable. It allows obtaining a coating with a strong substrate/polymer interphase without the need to use additional chemicals or multi-step processes. The work of Gibas et al. (Ref 38) highlights the feasibility of fabricating a superhydrophobic coating by combining cold-spray process, using fluorinated silica spheres as feedstock, and sol-gel technique. Also, the work of Ravi et al. (Ref 37) introduced a laser surface texturing treatment on the substrate to promote mechanical interlocking, has substantially increased the deposition efficiency to $15 \%$ although such process requires additional time and cost. The resultant coating showed super-hydrophobic properties and excellent water-repellency; however, no adhesion data was reported. These studies indicate that cold-spray technique can be seen as an alternative to fabricate functionalized polymer coating on polymer or metal substrates but with material modifications.

Hence, this research work aims to investigate the development and characterization of fluoropolymer cold-spray. The deposition behaviour is characterized through the deposition efficiency and measured as a function of various experimental conditions, such as pass number and traverse speed. The role of crystallinity and particle size is also discussed. The influence of the addition of octylsilane treated fumed nano-ceramic into the fluoropolymer feedstock on the deposition efficiency was studied. Lastly, the coating microstructure was analyzed by 
scanning electron microscopy, and its hydrophobic properties were characterized by sessile droplet contact angle measurements.

\section{Materials and Methods}

2.1 Feedstock powder, fumed nano-ceramic particles and substrate

Two grades of fluoroethylene propylene (FEP) powders were used in this study. They come from DuPont K.K. (referenced as 532G-8100 FEP (Ref 39)) and The Chemours Company (referenced as Teflon FEP 140 (Ref 40)). The particles were sieved separately before coldsprayed using Retsch AS200. Three mean sizes are investigated in this study: 10, 30, and $100 \mu \mathrm{m}$ The mechanical and physical properties of the material is provided in Table 1.

Table 1 Mechanical and physical properties of the semi-crystalline fluoroethylene propylene used in this study.

\begin{tabular}{lcc}
\hline Parameter & Unit & Value \\
\hline Density at $20^{\circ} \mathrm{C}(\operatorname{Ref} 40)$ & $\mathrm{g} / \mathrm{cm}^{3}$ & $2.12-2.17$ \\
Melting point (Ref 40) & $\mathrm{K}$ & $576-586$ \\
Heat of fusion (DSC) (Ref 40) & $\mathrm{J} / \mathrm{g}$ & 9.8 \\
Crystallinity (Ref 41) & $\%$ & $40-70$ \\
Glass transition temperature (Ref 41) & $\mathrm{K}$ & 353.2 \\
\hline
\end{tabular}

The fumed nano-ceramic (FNC), like fumed nano-silica (FNS) and fumed nano-alumina (FNA), whether hydrophilic or hydrophobic, is a common additive in powder coating to enhance and optimize the manufacturing, quality and performance of the coating. In a lowpressure cold-spray (LPCS) process, the addition of FNC may also help to enhance the flowability of the particles. This effect is caused by the surface charge of the FNC. These FNC have different tendencies towards either negative or positive charges Strong negative or positive surface charge may cause the FNC to aggregate and/or agglomerate, in which an increase in its particle size from agglomeration may be observed. The FNC used in this study is hydrophobized type: silica R805 (Ref 42) and alumina Alu C 805 (Ref 43), obtained from 
Nippon Aerosil Co. Ltd., Japan (hereinafter referred to as FNS and FNA, respectively). According to the manufacturer, the former is a product of flame hydrolysis of silicon tetrachloride $\left(\mathrm{SiCl}_{4}\right)$ in an oxyhydrogen gas flame and then hydrophobized using octylsilane. Similarly, the latter is a product of flame hydrolysis of aluminum chloride on an oxyhydrogen gas flame which was hydrophobized (Ref 42 ). These products are commercially available in both untreated (hydrophilic) and treated (hydrophobic) type. For hydrophilic type, no additional treatment is needed as the by-products are already hydrophilic. Aerosil products like hydrophilic fumed nano-silica, the pervasive silanol group on the surface renders its hydrophilicity and the concentration of silanol increases with increasing the specific surface area (Ref 42). The manufacturer specification is described in Table 2. For the mixed feedstock powder preparation, a $5 \mathrm{wt} . \%$ of each FNC (approximately $2.5 \mathrm{~g}$ ) was mixed with $50 \mathrm{~g}$ FEP particles in a $100 \mathrm{ml}$ EtOH solvent (99.6\% Sigma Aldrich) in a $250 \mathrm{ml}$ beaker. Hereinafter, the FNS and FNA mixtures are referred to as F5S and F5A, respectively. The weight percentage of the fumed nano-ceramics was determined based on the work of Ravi et al. (Ref 27). A homogenizer and a stirrer were used for 3 hours at room temperature and air-cooled to dry. Specific care was taken during the powder processing stage since inadequate drying will result in coating inhomogeneity. A commercially available pure aluminum substrate, A1100, was cut into a square coupon of $30 \times 30 \times 5 \mathrm{~mm}$ and cleaned using an ultrasonic bath. The mean roughness, $R_{a}$, and the maximum height of the profile, $R_{z}$, of the as-received A1100 substrate is $0.45 \pm 0.15 \mu \mathrm{m}$ and $2.45 \pm 0.29 \mu \mathrm{m}$, respectively.

Table 2 Material properties of hydrophobic fumed nano-ceramics (Ref 42,43).

\begin{tabular}{lccc}
\hline Parameter & Unit & \multicolumn{2}{c}{ Value } \\
Grade & & R805 & Alu C805 \\
& & (FNS) & (FNA) \\
Primary size & $\mathrm{nm}$ & $20-50$ & $7-20$ \\
Specific surface area BET & $\mathrm{m}^{2 /} \mathrm{g}$ & $150 \pm 25$ & $90 \pm 15$ \\
Surface treatment (hydrophobization) & & \multicolumn{2}{c}{ Octylsilane }
\end{tabular}




\begin{tabular}{lccc} 
Density at $20^{\circ} \mathrm{C}$ & $\mathrm{g} / \mathrm{cm}^{3}$ & 2.2 & 3.2 \\
Melting point & $\mathrm{K}$ & 1973.15 & 2323.15 \\
Surface charge & & Negative & Positive \\
\hline
\end{tabular}

\subsection{Cold-spray conditions}

A commercially available low-pressure cold spray system, Dymet 423 (Obninsk Center for Powder Spraying, Russia) was employed in this study. The cold-spray system was connected to a screw-type compressor unit and a dryer for air compression (up to $1.2 \mathrm{MPa}$ ). Besides ambient air, the system also utilizes nitrogen gas (up to 1.0 MPa). The operating temperature can be controlled from room temperature $(\mathrm{RT})$ to $873 \mathrm{~K}$. Although the maximum gas flow rate is $600 \mathrm{~L} / \mathrm{min}$ at room temperature, it decreases with increasing gas temperature. A standard vibrational type feeder was utilized to control the feeding rate at a consistent value of $0.1 \mathrm{~g} / \mathrm{s}$. By design, the particles were fed into the divergence part of the De Laval nozzle due to the difference in pressure between feeder end and particle inlet at the nozzle. The nozzle dimension of the convergence-divergence part is shown in Fig. 1. The convergence part including the throat is $19 \mathrm{~mm}$ long with a gas inlet diameter of $8.8 \mathrm{~mm}$ where compressed and heated gas flows through into the throat with an inlet diameter of $2.6 \mathrm{~mm}$ which gradually increase to $3.24 \mathrm{~mm}$. The divergence part is $120 \mathrm{~mm}$ in length, with an increasing diameter from $4.0 \mathrm{~mm}$ near the particle inlet and $4.8 \mathrm{~mm}$ at the end. The particles flow into the nozzle via the particle inlet at the beginning of the divergence part with a diameter of $1.0 \mathrm{~mm}$.

The influence of the gas temperature, traverse speed and pass number on the coating quality is investigated. Details of the cold-spray parameters used in this study are presented in Table 3. To prevent direct heat accumulation on the substrate surface by the nozzle before the coldspray, the nozzle was positioned outside the substrate. Thus, a small amount of powder is not sprayed directly on the substrate. Therefore, when determining the deposition efficiency, we did not consider in our calculation the weight of particles sprayed outside of the substrate. 


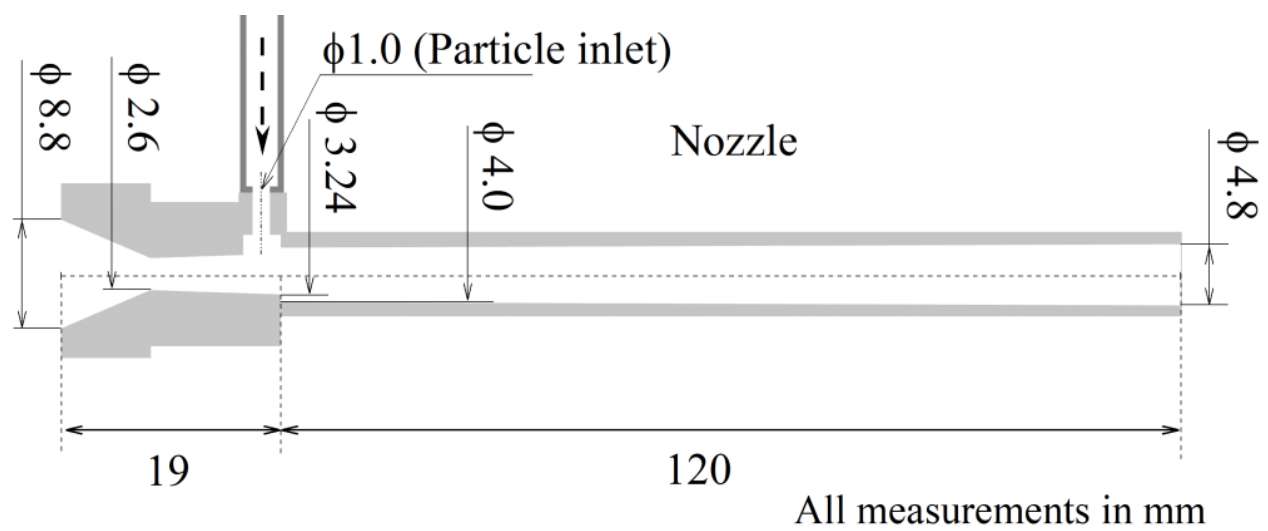

Fig. 1 Schematic representation of nozzle used in this study.

Table 3 Spray conditions.

\begin{tabular}{lcc}
\hline Parameter & Unit & Value \\
\hline Gas nature & & Air \\
Gas temperature, $T_{\text {gas }}$ & $\mathrm{K}$ & $373-773$ \\
Gas pressure, $P_{\text {gas }}$ & $\mathrm{MPa}$ & 0.5 \\
Standoff distance, $S D$ & $\mathrm{~mm}$ & 10 \\
Traverse speed, $T S$ & $\mathrm{~mm} / \mathrm{s}$ & $5,10,50$ \\
Number of passes & & $1,2,4,16$ \\
\hline
\end{tabular}

\subsection{Powder and coating characterization}

The morphology and microstructure characterizations of the particles and coating are performed using a field emission scanning electron microscopy (SEM), Hitachi FE-SEM SU70. The elemental composition of randomly selected F5S and F5A are analyzed using the energy dispersive x-ray (EDX) line scan to evaluate the distribution behaviour of the fumed nano-ceramics particles over the FEP particles. Characteristic X-rays were detected for discrete positions along the line under identical beam conditions $(5 \mathrm{kV}, 43 \mu \mathrm{A})$ and magnification $(3000$ times). All samples are analyzed at low voltage to avoid FEP particles to charge up during the process.

The deposition behaviour of FEP particles on the Al substrate at different temperatures was studied using the field emission-SEM and focused ion beam (FIB), Hitachi FB2200. The region of interest of the deposited particle was removed using the FIB and analyzed using the SEM. 
X-ray diffraction (XRD) of particles was measured using Shimadzu MAXima_X XRD-7000. $\mathrm{Ni}$-filtered copper line radiation $(\mathrm{Cu}-\mathrm{K} \alpha)$ at accelerating voltage of $40 \mathrm{kV}$ and current of $30 \mathrm{~mA}$ was used. The measurement was conducted at room temperature, $2 \theta$ angle range of $10-30^{\circ}$ with 0.02 step size.

The measurement of zeta potential of as-received FEP particles and octylsilane treated FNS and FNA particles was performed using an electroacoustic sensor and a titration system (Dispersion Technology, DT-300) at room temperature (298 K). Measurement of the fumed nano-ceramics was conducted in a mixture of $\mathrm{HCl}$ and $\mathrm{EtOH}(1: 1)$ using $0.01 \mathrm{M} \mathrm{KCl}$ as a calibration solution. The measurement was conducted for $\mathrm{pH}$ ranging from 3 to 13 . The advantage of the electroacoustic method is the ability to perform accurate measurements without the need to dilute the samples (Ref 44,45). Dilution of samples such as a hydrophobic fumed nano-particle may be difficult and challenging using the conventional method.

The melting and crystallization behaviour of the as-received FEP particles were evaluated using a differential scanning calorimetry (DSC), Rigaku DSC8231, in a nitrogen gas atmosphere (flow rate of $100 \mathrm{~L} / \mathrm{min}$ ). Two heating-cooling runs from $293 \mathrm{~K}$ to $560 \mathrm{~K}$ were performed with a heating rate of $10 \mathrm{~K} / \mathrm{min}$. Each sample was weighted $5.0 \pm 0.3 \mathrm{mg}$ and $\alpha$ alumina powder was used as a reference. Using DSC, we also measured the degree of crystallinity, as well as the characteristic temperatures and heat of fusion of the FEP particles. The degree of crystallinity of as-received FEP particles is determined using (Eq 1 as the ratio of the observed heat of fusion $\mathrm{H}_{\mathrm{f}}^{\mathrm{o}}$ to the theoretical heat of fusion for $100 \%$ crystalline polytetrafluoroethylene (PTFE) or Teflon $\mathrm{H}_{\mathrm{f}}^{100 \%}=82 \mathrm{~J} / \mathrm{g}(\operatorname{Ref} 46-48)$ :

$$
\% \chi_{\text {cry }}=\frac{\mathrm{H}_{\mathrm{f}}^{\mathrm{o}}}{\mathrm{H}_{\mathrm{f}}^{100 \%}} \times 100
$$


The roughness profile of the substrate before and after cold-spray was analyzed using contacttype surface profiler (Kosaka Laboratory Surfcorder SE-300). The diamond stylus tip radius was $2 \mu \mathrm{m}$ and vertical measuring range was $800 \mu \mathrm{m}$. Five measurements along a $25 \mathrm{~mm}$ length on the surface were taken to determine the arithmetical mean surface roughness, $R_{a}$ and the average maximum peak to valley, $R_{z}$.

\subsection{Particle velocity}

The velocity of the in-flight particles, $v_{p}$, at the nozzle exit was measured using an OSEIR SprayWatch system. Combining a fast shutter CCD camera and of a high powered pulse-laser diode (HiWatch), the system captures the particle velocity at the nozzle exit and before the impact on the substrate (Ref 49). Measurements are performed using the $30 \mu \mathrm{m}$ sized asreceived FEP particles from room temperature to $773 \mathrm{~K}$ and $0.5 \mathrm{MPa}$ of inlet gas temperature and inlet gas pressure, respectively.

\subsection{Substrate temperature measurement}

The substrate temperature measurement was performed using a high resolution and multipurpose infrared thermal image camera, Nippon Avionics Co., Ltd. The measurement of the substrate surface was measured in the range of 313 to $773 \mathrm{~K}$, with a sensitivity of $\pm 0.03 \mathrm{~K}$ and accuracy of $\pm 1.0 \mathrm{~K}$. The emissivity of the A1100 substrate, $E_{A l}(=0.15)$ (Ref 50), is much lower than other metallic substrates. The temperature of the substrate, $T_{s u b}$, was measured without feeding the particle. The camera was positioned at a $45^{\circ}$ angle to the nozzle and the substrate surface.

\subsection{Deposition efficiency measurement}


Deposition efficiency for five samples is measured as the ratio between the deposited weight of particles versus the sprayed weight of particles:

$$
D E(\%)=\frac{\text { Deposited weight }}{\text { Sprayed weight }} \times 100 \%
$$

For each investigated spray condition, the mean values and the standard deviation are calculated. As mentioned before, the weight of particles sprayed outside the substrate was excluded when determining the deposition efficiency.

\subsection{Contact angle measurement}

The characterization of the wettability of FEP coating on different substrates surfaces was performed on a dynamic contact angle measurement, Kyowa Interface Science SA-301. Droplet size of $10 \mu \mathrm{m}$ was used in each test. To investigate the discrepancy of the wettability experiments and the homogeneity of the coating surface, the experiment was repeated 10 times on different areas of the coating surface. To ensure precise control of the tilt angle, the sample stage was managed remotely. The stage was tilted up at a rate of $0.1 \%$ step, to a 90 -degree angle before another round of test was performed. The roll-off angle $\left(\theta_{r o}\right)$ is defined as the stage inclination angle at the onset of droplet sliding/rolling from its static position. The advancing and receding angles $\left(\theta_{a}, \theta_{r}\right)$ are defined as the angle measured at between the solid-liquid interface (the leading-edge) and liquid-vapour interface (the preceding edge) at the onset of sliding/rolling off (Ref 51). The wettability properties of a fluoropolymer surface are extensively studied and reviewed (Ref 52-54). The hysteresis angle, $\theta_{h}$, is defined as the difference between the advancing and receding angle, which stated in (Eq 3;

$$
\theta_{h}=\theta_{a}-\theta_{r}
$$

3. Results and Discussion 
3.1 As-received FEP and fumed nano-ceramic mixed FEP particles characterization

The characterization of the feedstock particles was performed using SEM to qualitatively analyze the morphological differences as the effect of the FNC addition. A homogenous network of FNC distribution on the FEP particles is favourable in increasing the efficiency of coating build-up during cold-spray (Ref 23).

Topography of the three feedstock powders, pure FEP, F5S and F5A, are shown in Fig. 2. Pure FEP powder in Fig. 2(a), exhibits an irregular shape and some in dish-shaped; some much smaller particles are also seen in between the larger ones. No evident agglomerated FEP particles on top of each other are seen. The particles have a combination of the smooth and coarse surface. For the FEP particles with FNC addition, distribution behaviour of the FNS and FNA nano-particles are presented in Fig. 2(b) and (c), respectively. In Fig. 2(b), flocculant of agglomerated FNS on the FEP particles are evident (marked by arrows). The flocculants are formed from the agglomeration of FNS when suspended in EtOH. Such flocculation generally associated with the attraction force between the silanol group on the surface of the FNS particle. The resultant mixture of F5S indicated that the FNS is sparsely distributed on FEP, thus more exposed FEP surface can be seen. On the contrary, FEP mixed with FNA in Fig. 2(c), indicated different distribution behaviour of these FNC after the mixing process. As indicated in Table 2, the primary size and specific surface area of the FNA is smaller than the FNS. Although the specific surface area is influenced by porosity, it also is influenced by size, shape, and roughness if the particle has low or no porosity. The ratio of the specific surface area to primary particle size in FNS being comparatively lower than FNA, FNS shows that it is porous by nature. As illustrated in Fig. 2(b), FNS is susceptible to aggregation resulting from the environment $\mathrm{pH}$, in which the mixture to obtain $\mathrm{F} 5 \mathrm{~S}$ is done. Combination of the size of the aggregates and the surface charge contributes to the homogenous distribution of the FNA on the FEP surface compared to the FNC as previously stated by Lock Sulen et al. (Ref 30). 


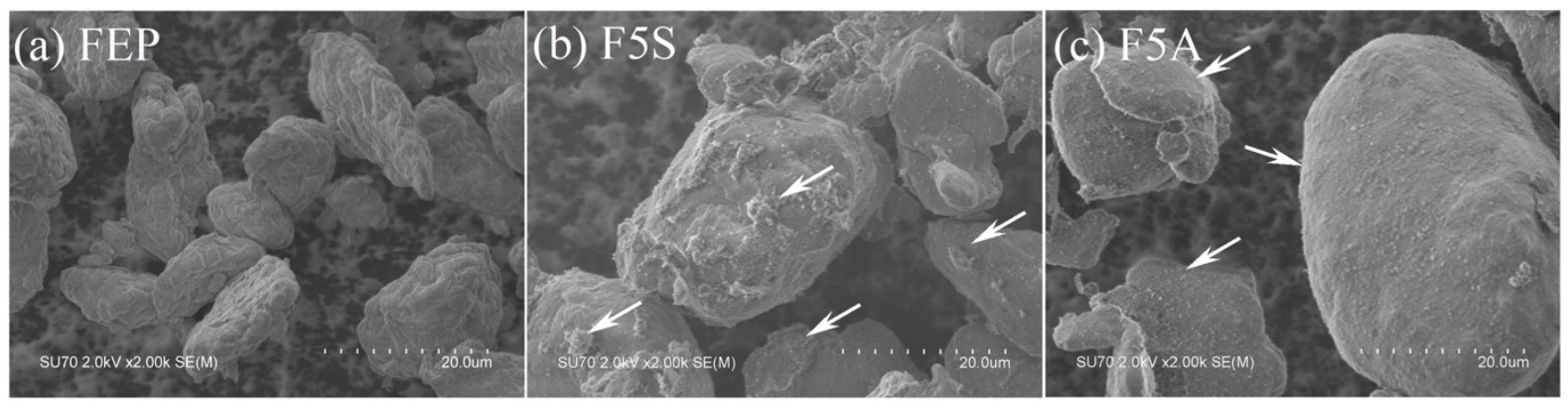

Fig. 2 SEM images of (a) as-received pure FEP particles, (b) F5S, and (c) F5A. Flocculants (marked by arrows) evident in F5S in contrast to finely dispersed FNA (marked by arrows) in F5A.

The difference in the elemental distribution between F5S and F5A is qualitatively analyzed using energy dispersive X-ray (EDX) line scan. The intensity for each elemental x-ray characteristic, plotted along the scanning line, shows a variation of the element dispersion. Results and SEM image of the selected particles (inset) are presented in Fig. 3. High intensity of the fluorine $(\mathrm{F})$ and carbon $(\mathrm{C})$ is measured on both F5S and F5A surfaces due to the chemical composition of the FEP particles. In addition to these two elements, the presence of FNA represented by aluminum (Al) and oxygen $(\mathrm{O})$ in F5A; and FNS by Silica ( $\mathrm{Si}$ ) and oxygen (O) in F5S are also detected (Fig. 3(a) and (b), respectively). The intensity of Al and O on F5A particle is high and consistent along with the scanning line. However, the intensity of Si and O is seen higher at the beginning, indicated by a peak where flocculants of FNS on the F5S can be seen. The value decreased and remained low compared to $\mathrm{C}$ and $\mathrm{F}$ for most of the scanning line. This trend suggests that the FEP particle is not entirely covered by the FNS compared to FNA even though similar weight percentage of each FNC was added to the FEP. From a quantitative viewpoint, it is difficult to precisely evaluate the distribution of the FNC on the FEP particle due to the tendency to charge up. This may lead to poor image quality and inconsistent results. 
Therefore, based on these results, the distribution of FNA nano-particles on the FEP particle was found to be more homogenous by creating a finely dispersed network compared to FNS.

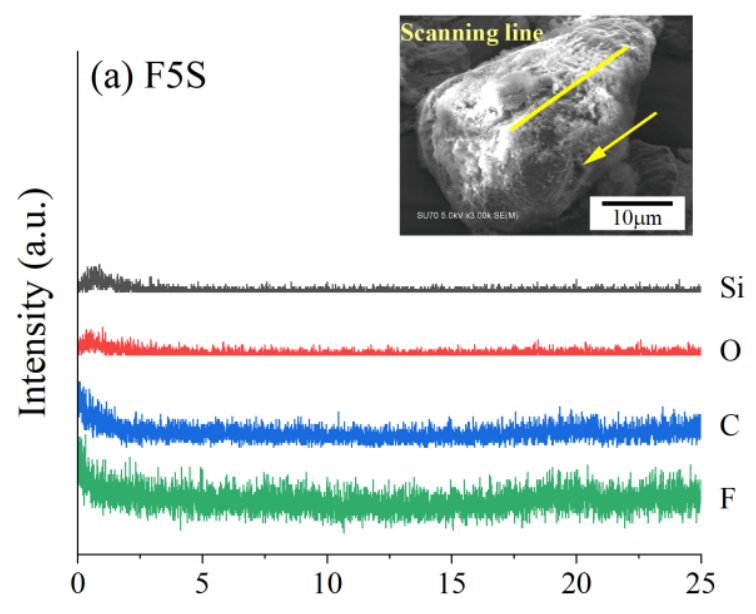

Along scanning line $(\mu \mathrm{m})$

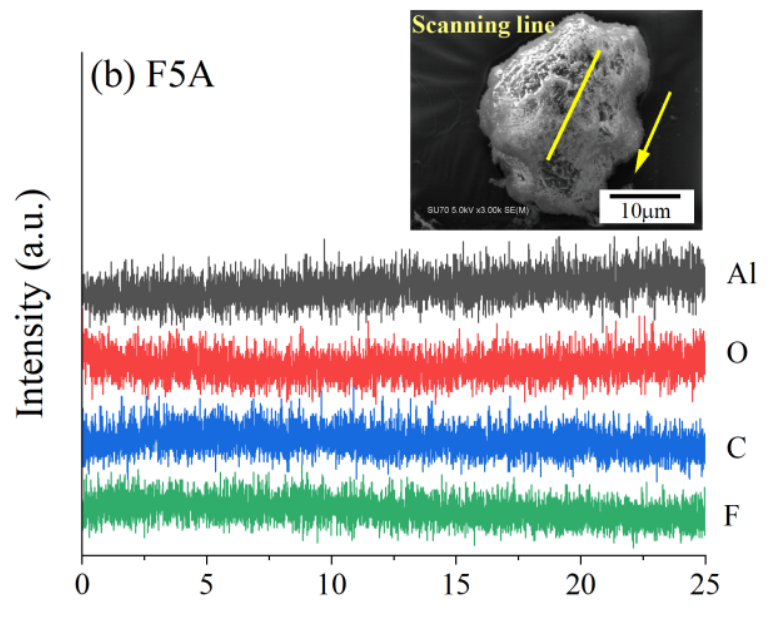

Along scanning line $(\mu \mathrm{m})$

Fig. 3 EDX line scan results of (a) F5S; and (b) F5A. Scanning direction (as indicated by arrow) was performed along the scanning line (yellow line).

To better understand the difference in the FNC distribution on the FEP surface, we investigate the particle surface charge in terms of zeta-potential. The zeta potential $(\zeta)$ or electrokinetic potential is the electric potential in the interfacial double layer at a slipping plane which is relative to a point in the bulk fluid away from the interface (Ref 55). The morphology and zeta potential of the fumed nano-silica has extensively been studied by V.M. Gun'ko et al. (Ref 56) or Chereches and Minea (Ref 57). The relationship of the zeta-potential in the function of the mixture $\mathrm{pH}$ is crucial to determine the isoelectric point (IEP) of the $\mathrm{FNC}$, which generally associated with the instability of particle behaviour in suspension.

Results of the measured zeta-potential and the isoelectric point of FEP, FNS, and FNA are shown in Fig. 4. The comparison between measured FNS and FNA in details is shown in the inset. The results indicate that the IEP for FEP, FNS and FNA are 6.2, 3.6 and 8.2, respectively. These IEP values for FNS and FNA are approximately closer to those of general values for commonly available silica and alumina particles (Ref 42). In contrast to the high zeta potential 
for FEP particle $\left(-50<\zeta_{\mathrm{FEP}}<+50\right)$, low zeta potential $\left(-7<\zeta_{\mathrm{FNS}}\right.$ or FNA $\left.<+5\right)$ is measured for the hydrophobized FNS and FNA. Low zeta potential in the hydrophobized nano-particles is associated with the untreated hydroxyl/silanol group on the FNC surface. It is assumed that the differences in distribution behaviour between FNS and FNA that was observed previously are related to the surface charge or zeta potential during the mixing process. EtOH used in the mixing process is an organic solvent and technically has a $\mathrm{pH}$ value of 7.3 (Ref 58). At this point, a repulsive force between the FNS and FEP particle is strong due to the same negative zeta potential. As a result, FNS particle agglomerated and attraction force to the FEP surface is weak. On the contrary, an attraction force between FNA and FEP particle due to the opposite zeta potential charge is observed. Despite the attractive force between these two particles, it should be only efficient until the accumulation of FNA particles reaches an optimal thickness. A repulsive force may prohibit succeeding layers to be distributed on the FNA covered FEP particle, resulting in an agglomeration of the FNA particles as well.

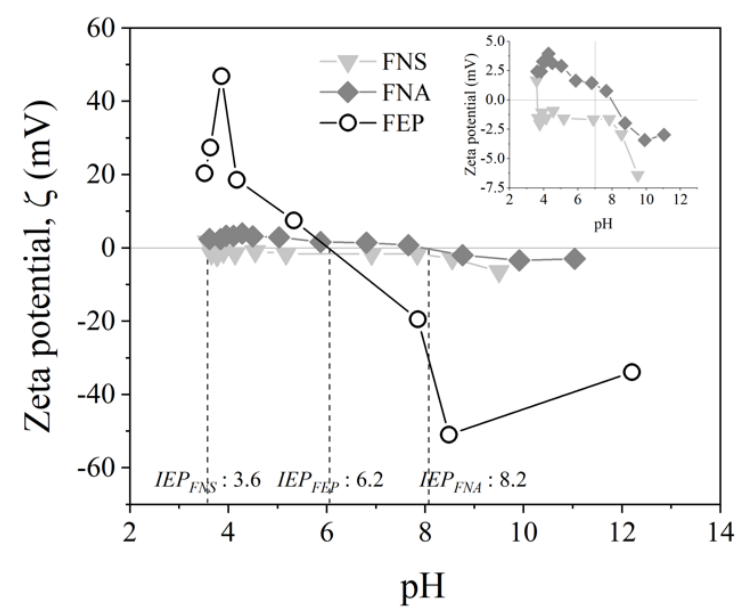

Fig. 4 Relationship between zeta potential in function of the solution $\mathrm{pH}$ for the FEP, and hydrophobized FNS and FNA (also shown in the inset). For each particle, the isoelectric point (IEP) is identified. 
Besides the modification of the feedstock particles, it is also important to measure the degree of crystallinity, $\% X_{c r y}$, of the host particle. Deformation of semi-crystalline fluoropolymer particles in a solid-state deposition impact is unknown mainly due to the strain rate involved and the viscoelastic behaviour of the material. Correlation between the degree of crystallinity and deposition behaviour of a fluoropolymer particle in LPCS provides insight about microstructure changes during cold spray. Using XRD and DSC analyses, the degree of crystallinity of three particle sizes of as-received FEP particle is determined. XRD results are presented in Fig. 5. The XRD diffractogram is characterized by a sharp peak, with the highest intensity, and a broad peak (Fig. 5(a)). The peak with the highest intensity $\left(2 \theta=18^{\circ}\right)$ is generally associated with the crystalline phase, in which the incident X-ray is diffracted by the plane (100) of the pseudohexagonal lattice structure in an FEP (Ref 41). On the contrary, the broad peak that superimposed the previous peak, which reach its maximum at $2 \theta=16.5^{\circ}$, is associated with the amorphous structure of the FEP particles. According to Herman and Weidinger (Ref 59,60) and after deconvolution of the two peaks, the degree of crystallinity is determined from the integration of the area under the peak linked to the crystalline phase $A_{\text {cry }}$ and the one linked to the amorphous phases $A_{a m}$ :

$$
\% \chi_{c r y}=\frac{A_{c r y}}{\left(A_{c r y}+2.17 A_{a m}\right)} \times 100
$$

The deconvolution was performed using a Gaussian function on the XRD diffractogram and results are presented in Fig. 5(b). With a degree of crystallinity of $25.1 \pm 0.5 \%$, the $30 \mu \mathrm{m}$ FEP particles show the highest degree of crystallinity among the three particle size studied. Thus, the FEP used in this study is highly amorphous. 

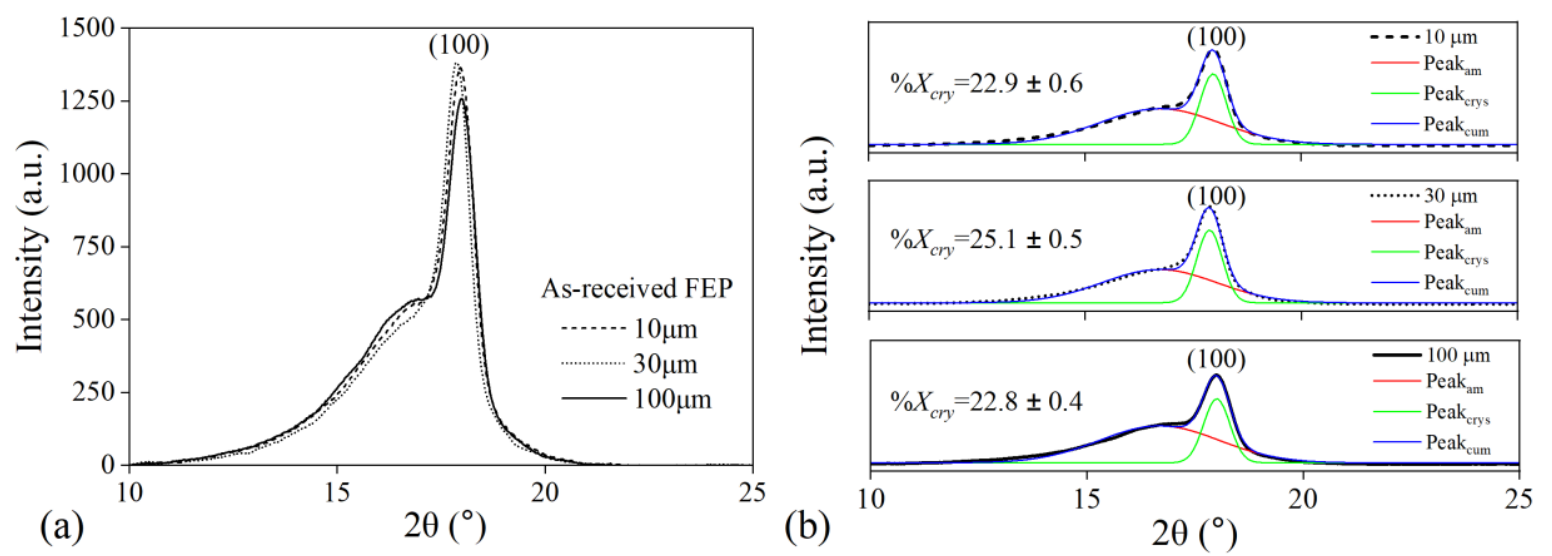

Fig. 5 X-ray diffractogram of (a) as-received FEP particles of different mean sizes 10, 30 and $100 \mu \mathrm{m}$. (b) Deconvolution of the X-ray diffractogram and identification of the degree of crystallinity for the three mean-size of FEP particle studied.

For the three particle sizes studied, the DSC results are presented in Fig. 6. From these results, the glass transition temperature of each particle (represented by $T_{g 10}$ for $10 \mu \mathrm{m}, T_{g 30}$ for $30 \mu \mathrm{m}$ and $T_{g 100}$ for $100 \mu \mathrm{m}$ ) is determined from the deviation in the heat flux of the first heating. The glass transition temperatures obtained for $10 \mu \mathrm{m}$ and $30 \mu \mathrm{m}$ are in the range of $442.4 \pm 16.7 \mathrm{~K}$ 445.2 $\pm 10.2 \mathrm{~K}$. Higher glass transition temperature was observed in $100 \mu \mathrm{m}$ particle at 455.1 $\pm 20.5 \mathrm{~K}$. All values are comparatively higher than the literature values in Table 1. Under identical heating conditions $(10 \mathrm{~K} / \mathrm{min})$, the melting temperature of all the particles(represented by $T_{m 10}$ for $10 \mu \mathrm{m}, T_{m 30}$ for $30 \mu \mathrm{m}$ and $T_{m 100}$ for $100 \mu \mathrm{m}$ ) was in the range of 521 to $529 \mathrm{~K}$ which is within range in comparison to the data found in the literature (Table 1).

The degree of crystallinity of FEP particles, determined using (Eq 1) and measured for 10 and $100 \mu \mathrm{m}$ particles, is comparatively lower than the $30 \mu \mathrm{m}$ particle. A similar trend is observed in the degree of crystallinity measured using XRD and DSC is described in Fig. 6. The discrepancies in the degree of crystallinity between $30 \mu \mathrm{m}$ particle and the other particle sizes may arise from differences in the polymerization process at the manufacturing stage. These fluoropolymers are commercially available under different grade name as indicated in Table 1. 
Heat of fusion measured values are higher by two-fold compared to Table 1 , specifically $10 \mu \mathrm{m}$ and $30 \mu \mathrm{m}$ FEP (Teflon FEP 140). To have a better insight into the material properties during cold-spray, we consider here the value given by the first heating run instead of the second one as it is usually done in DSC. Thus, some differences arise between the values observed in the literature and the one found here as it is the case for the heat of fusion, which is generally associated with the measured value of a melt-crystallized sample. The degree of crystallinity is measured from the first heating peak considering the thermal history of the particle in a coldspray nozzle imparts by the gas temperature.

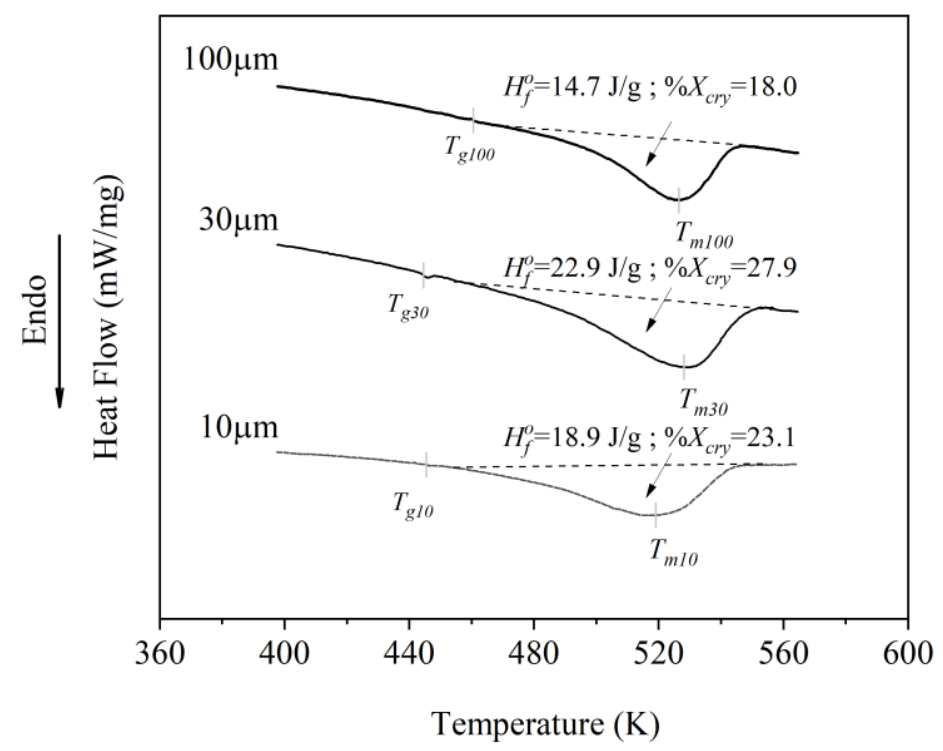

Fig. 6 DSC results for FEP particles The glass transition temperature, $T_{g}$, is marked by an endothermic deviation of the heat flow and the melting temperature, $T_{m}$, is characterized by an endothermic peak.

The surface morphology of the cold-sprayed substrate is reported in Fig. 7. During coldspraying, the mean roughness, $R_{a}$, and the maximum height of the profile, $R_{z}$, increase significantly compared to the as-received substrate. These values become constant with increasing pass number. The differences in surface roughness for each particle size is correlated to differences in the amount of plastic deformation imparted on the substrate surface by each 
particle. The plastic deformation is induced by the particle kinetic energy, which is higher in smaller particle under similar spray condition. At higher pass number, the surface roughness values become constant due to the peening effect of the particle. In other words, the substrate surface becomes hardened at this point and no longer susceptible to impaction-induced deformation by incoming particles.
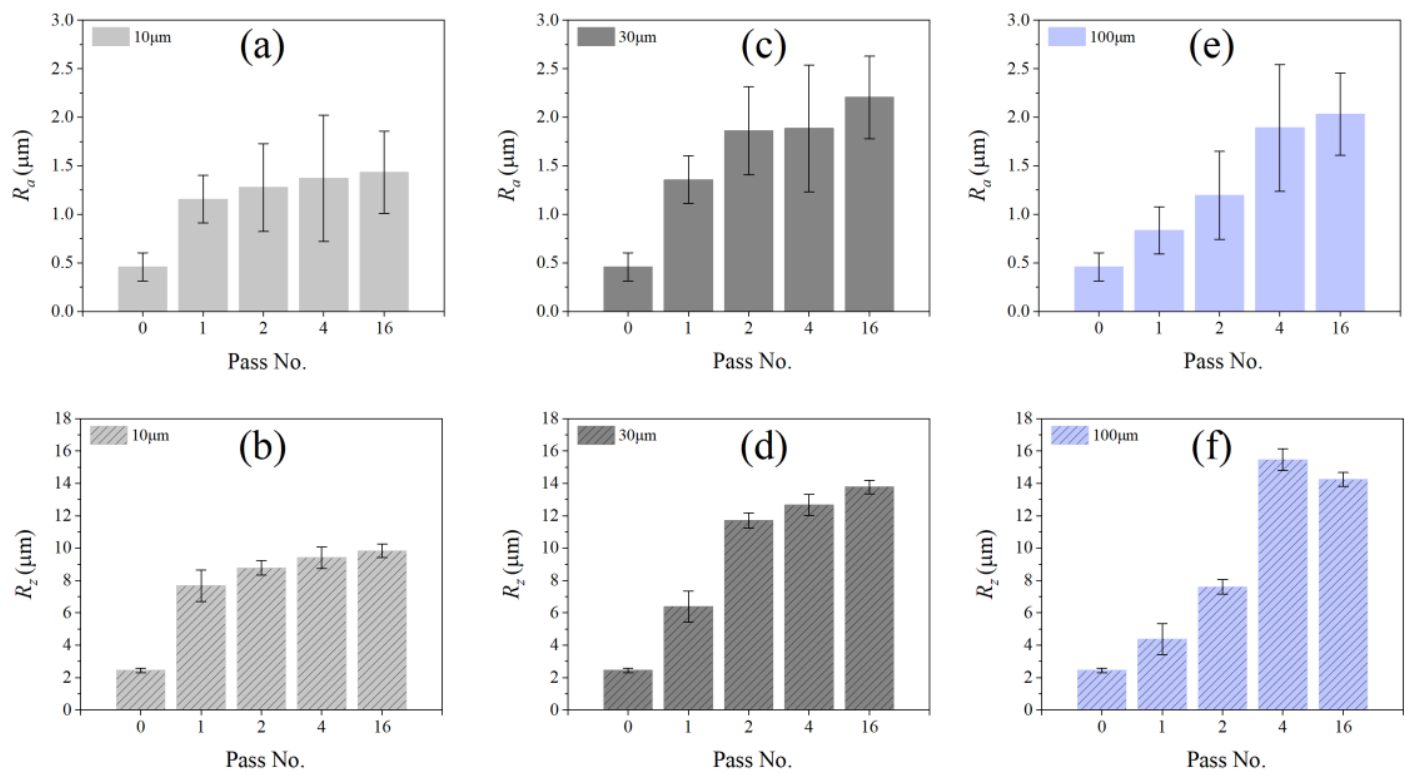

Fig. 7 Mean roughness, $R_{a}$ and the maximum height, $R_{z}$, of cold-sprayed A1100 substrate in the function of pass numbers for (a-b)10 $\mu \mathrm{m}$, (c-d) $30 \mu \mathrm{m}$, and (e-f) $100 \mu \mathrm{m}$.

\subsection{Deposition behaviour of the as-received FEP and FNC mixed FEP}

Deposition behaviour of the as-received FEP, F5S (5 wt.\% FNS mixed FEP) and F5A (5wt.\% FNA mixed FEP) on the Al substrate are investigated by analyzing the deformation behaviour of the particles after impact. Deposition efficiency and adhesion layer are also investigated. A deformed $10 \mu \mathrm{m}$ FEP particle deposited on the Al substrate under two different gas temperatures is shown in Fig. 8. Under an inlet gas temperature of $373 \mathrm{~K}$, the deformation of the particle (Fig. 8(a)) and the presence of splats in the vicinity of the particle suggest severe plastic deformation of the FEP. At such inlet gas temperature, the particle temperature remains 
below the glass transition temperature of the polymer $\left(T_{g}=442.4 \pm 16.7 \mathrm{~K}\right.$, see Fig. 6). Thus, before the impact, the FEP particle exhibit a glassy behaviour where the gas temperature is not enough to initiate melting of the particle surface. Under this condition, the measured substrate surface temperature and particle velocity was $300 \mathrm{~K}$ and $310 \mathrm{~m} / \mathrm{s}$, respectively. Thus, it is obvious that the plastic deformation-induced localized temperature rises which reduced the total energy necessary for the plastic deformation of the particle to occur. Although the localization of the temperature rise played a huge role in the plastic deformation, the subsequent interfacial temperature necessary for a strong adhesion was not observed. A weak adhesion was expected from the gap (marked by red arrows) observed at the interface as seen in Fig. 8(a). The particle may have adhered to the substrate surface by a partially melted interface, due to adiabatic self-heating occurring during the plastic deformation of the particle. A similar weak interface was observed on particle deposited at a higher gas temperature $(573 \mathrm{~K})$ as shown in Fig. 8(b). No cohesive bond or mechanical interlocking effect was observed as well. Adhesion of the particle, in particular, was mainly supported by the melted part of the outer area that formed filament-like structures (arrow in Fig. 8(b)). These filament-like structures are weak and did not cohesively bond with the substrate, thus, weak adhesion at the interface is expected. The particles were sprayed at high traverse speed, which enables a small number of particles to be deposited on the substrate surface. At this high traverse speed $(50 \mathrm{~mm} / \mathrm{s})$, no deformation of the substrate surface is evident. This shows that deformation of substrate surface only occurs by continuous impact from the incoming particles at slower traverse speed $(5-10 \mathrm{~mm} / \mathrm{s})$.

On the other hand, Fig. 9 shows the deposition images of F5A particles on a melted FEP layer top with finely dispersed FNA nanoparticles network on its surface. The micro/nano-structured layer provide an anchorage effect for the deposition of particle upon impact. Regardless, the FNA covered melted layer provide weak interlocking effect for the adhesion of the initial layers 
of F5A particle onto the surface. Hence, the adhesion strength is weak and the interlocking effect becomes null, offset by the coating weight leading to delamination when subject to the impinging gas and incoming particle impact. The nanocomposite layer was relatively similar to the as-received FEP particle in Fig. 8, as no mechanical interlocking effect or intact bonding, is observed. The nano-particle deposition was limited to the melted layer of the FEP (marked by arrows), a melted layer similarly found in Fig. 8 . These results show that the mechanics that govern the adhesion in polymer-metal differ considerably than metal-metal which in agreement to the discussion set forward by other studies (Ref 22,25,26,61).

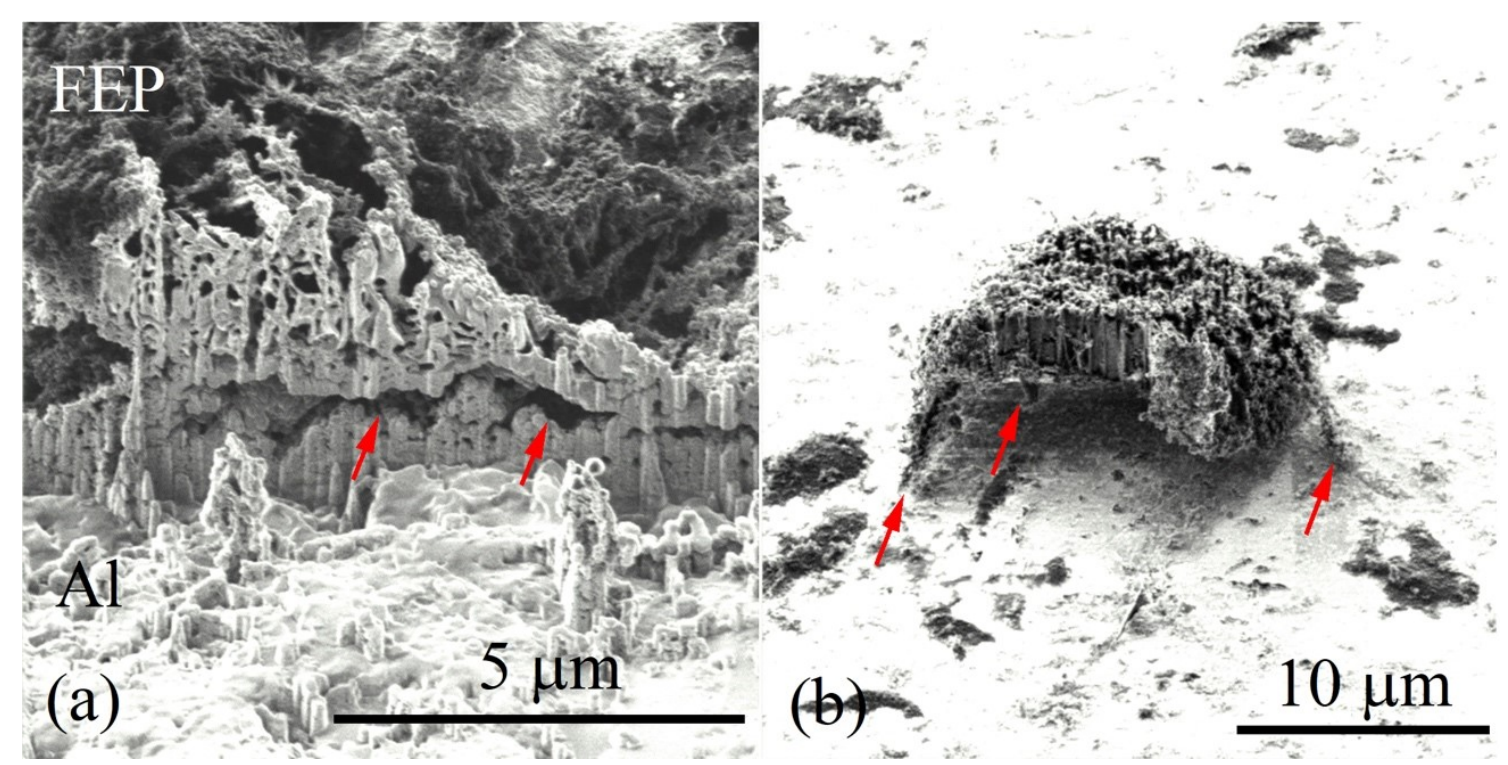

Fig. 8 Gap at the particle-substrate interface indicating a weak adhesion of the pure FEP particle after impact at (a) $373 \mathrm{~K}$; and (b) $573 \mathrm{~K}$ for a traverse speed of $50 \mathrm{~mm} / \mathrm{s}$ Arrows in (a) indicate gap at the particle-substrate interface; Arrows in (b) indicate filament-like structure holding the deposited particle onto the substrate surface. 

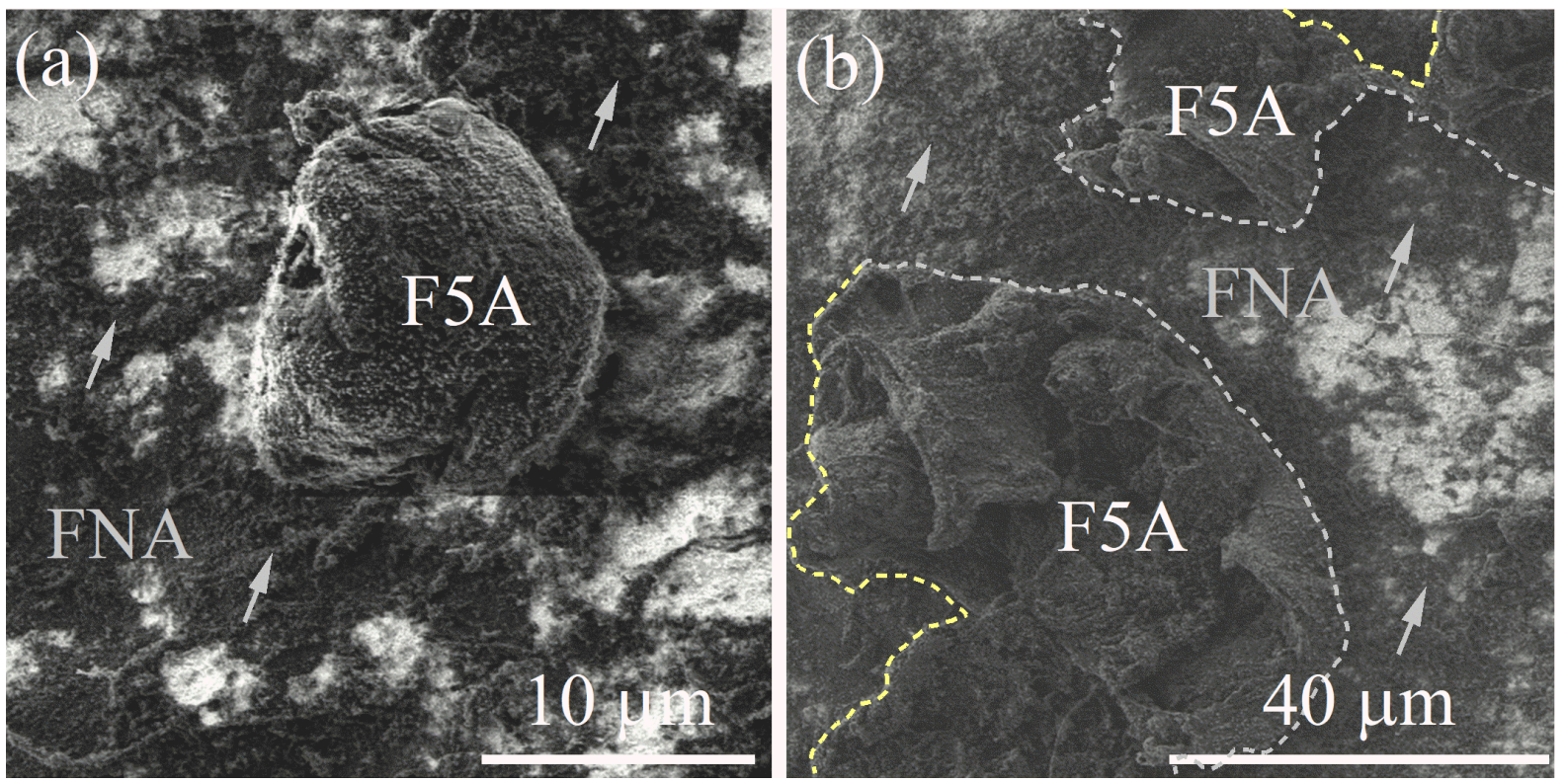

Fig. 9 SEM images of the deposited F5A particles at gas temperature of $573 \mathrm{~K}$, gas pressure of

$0.5 \mathrm{MPa}$ and traverse speed of $50 \mathrm{~mm} / \mathrm{s}$ for (a) Partially melted; and ( b) melted and deformed.

Bright area indicates Al substrate without melted layer and arrows indicate finely dispersed FNA on melted FEP layer.

Fig. 10 is the SEM images of different sizes as-received FEP particles cold-sprayed at $50 \mathrm{~mm} / \mathrm{s}$ under $373 \mathrm{~K}$. Melted layer of the deposited FEP particles were evident for (a) $10 \mu \mathrm{m}$; and (b) $30 \mu \mathrm{m}$, respectively. Beside melted layers, severe deformation was also observed in both but particularly comparable in the latter as the former was severely melted into a filament-like structure (arrows) and hard to compare with its initial shape. This filament-like structure is similar to the one observed in Fig. 8. Nonetheless, less to no evident deformation was observed on the substrate surface suggests no anchorage effect between particle-substrate to promote mechanically strong adhesion. On the contrary, only a small melted layer near the impacted surface (arrows) is seen in Fig. 10 (c). The partially melted layer suggested by the spallation of multiple melted pieces near the bottom part of the particle. However, no evident deformation of $100 \mu \mathrm{m}$ particle is observed. Also, no filament-like structures are observed in both images. 
Comparatively small kinetic energy for bigger particle due to low particle velocity appears to be insufficient to initiate plastic deformation on the entire particle.

Fig. 11 shows the deposition of several FEP particles on a deformed Al substrate surface in 2pass and 4-pass numbers. Adhesion of these particles is enhanced not only by the initiation of the melted layer but also substrate topological changes due to the plastic deformation from the continuous impact of particles. The results in Fig. 11 suggests deposition of the first layer for FEP particle below its glass transition temperature is possible, although their coating thickness and adhesion strength for practical use remain a huge challenge.

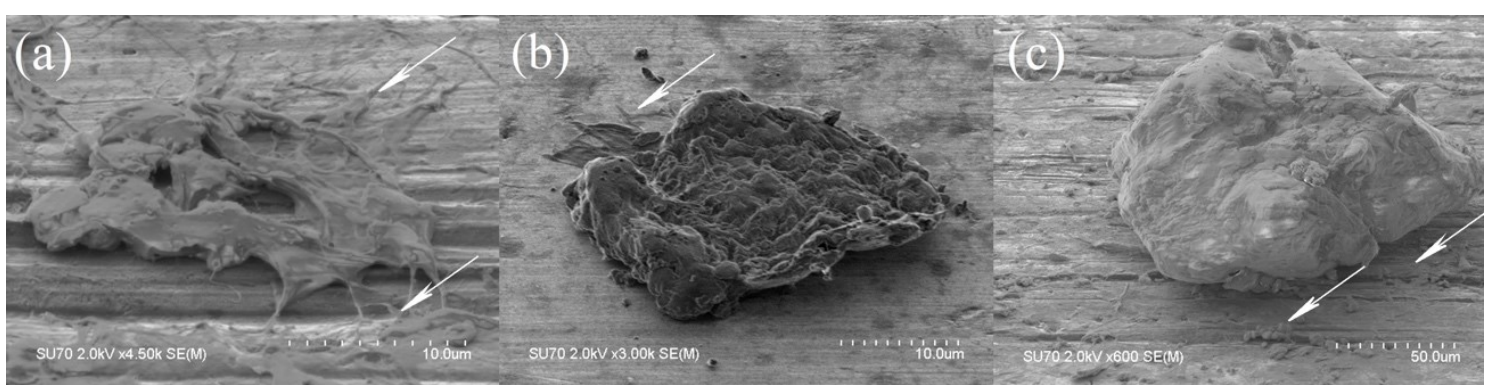

Fig. 10 SEM images of deposited as-received FEP particles on Al substrate at a traverse speed of $50 \mathrm{~mm} / \mathrm{s}$ and gas temperature of $373 \mathrm{~K}$. Arrows indicate melted layer from the deposited particle.

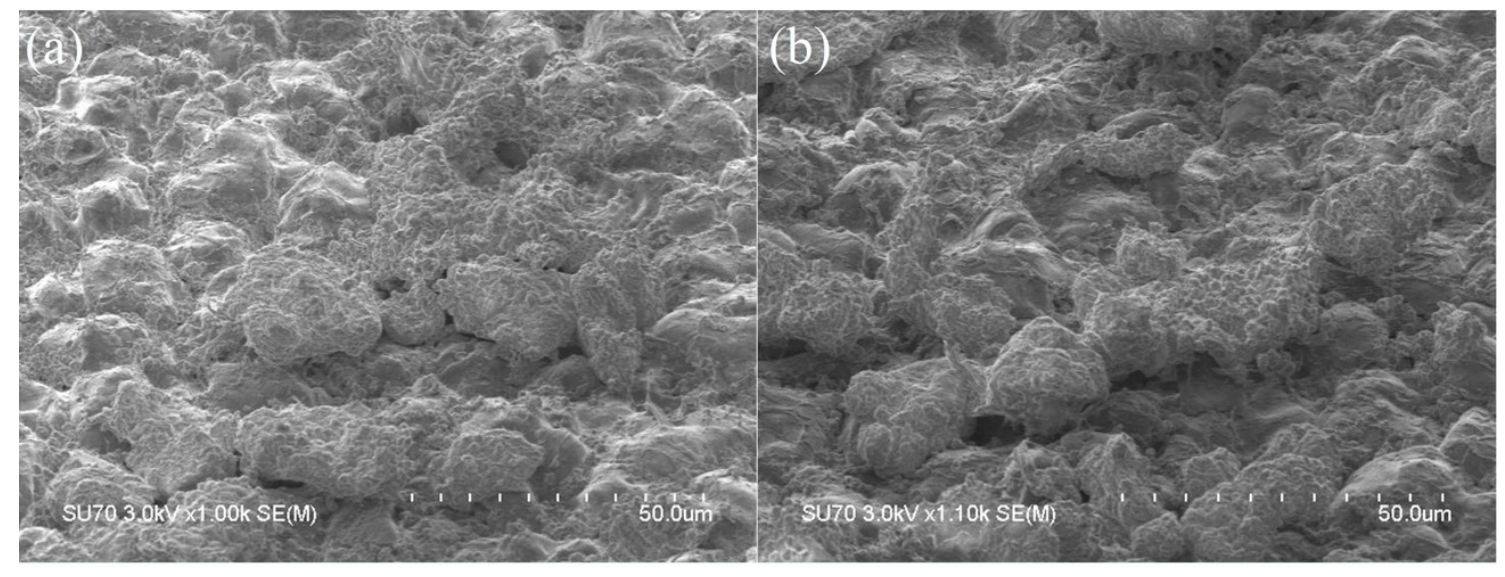

Fig. 11 Tilted SEM images of as-received FEP particle at (a) 2-pass and (b) 4-pass performed at a gas temperature of $773 \mathrm{~K}$ and a traverse speed of $5 \mathrm{~mm} / \mathrm{s}$.

Continuous spraying of FEP particles on the Al substrate is seen to induced surface roughening of the substrate, a similar effect found after a grit-blast process. Plastic deformation on the Al 
substrate is also observed on cold-sprayed samples as shown in Fig. 12. Peaks and valleys on a roughened substrate surface are observed in samples cold-sprayed by the $30 \mu \mathrm{m}$ sized particles. Loose deposition of FEP particle was also observed particularly between the peaks and easily identified by its bright colour from the subsequent charge-up by the accumulation of static electric charges (Ref 62). The changes on the peak surface are evident with increasing pass number. Smooth peak surface is seen in (a) in comparison to a course peak surface in (b).

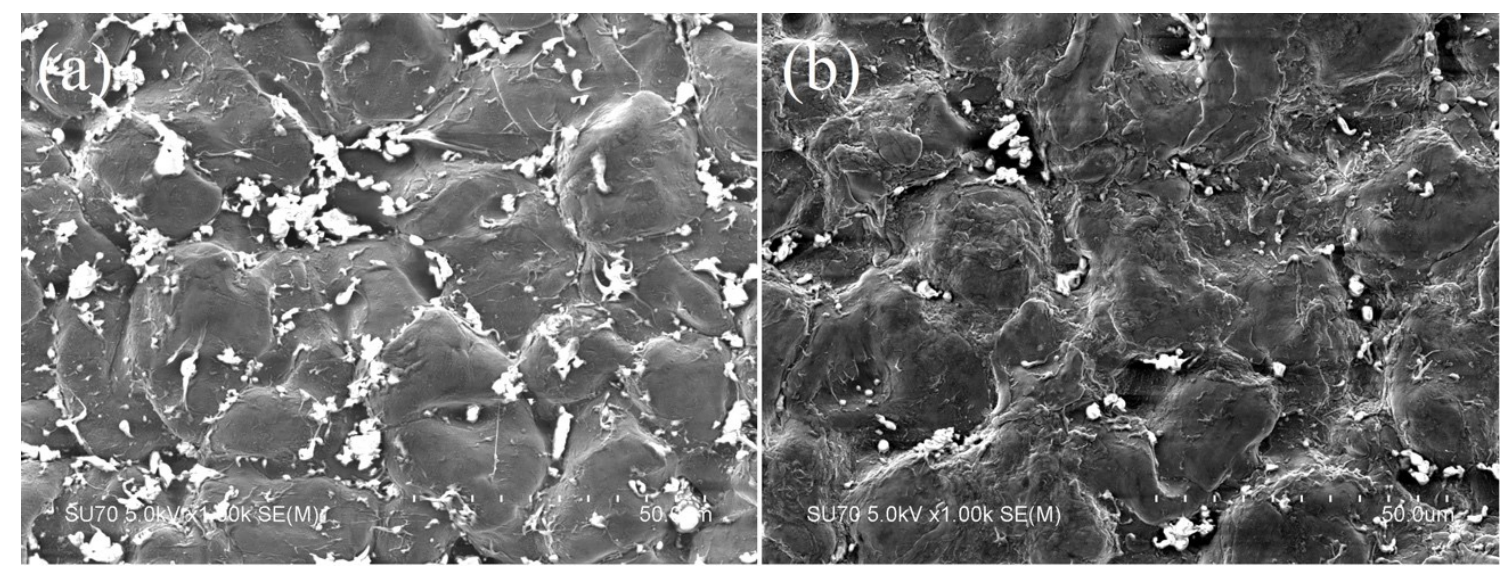

Fig. 12 SEM images of the cold-sprayed Al substrate surface in (a) 2-pass; and (b) 16-pass for $30 \mu \mathrm{m}$ of as-received FEP particles, performed at $5 \mathrm{~mm} / \mathrm{s}$ and $773 \mathrm{~K}$. Deposited layer of particles are indicated by the bright colour from the material charge-up.

Fig. 13 shows the deposited coating layer of the F5A using the $30 \mu \mathrm{m}$ particle and obtained after 2-pass, for a traverse speed of $5 \mathrm{~mm} / \mathrm{s}$, and gas temperature of $573 \mathrm{~K}$. Fig. 13(a) indicate F5A successfully formed a coating layer on the Al substrate. A coating thickness of less than $100 \mu \mathrm{m}$ was measured from the side-view image. It suggests that the FNA may have enhanced the coating build-up that works as a binder between the FEP particle (Ref 24). This coating layer is shown to be partially cohesive, leaving an evident gap between adjacent layer. Thus, exposed Al substrate peaks (marked by arrows) can be seen in Fig. 13(b). However, the top view image of the thickest part of the coating indicates cohesive deposition between FEP particles. Despite showing better coating thickness, the adhesion at the interface remained weak 
and inconsistent. Subsequent gas flow from the impinging gas and particle could easily delaminate the deposited coating.

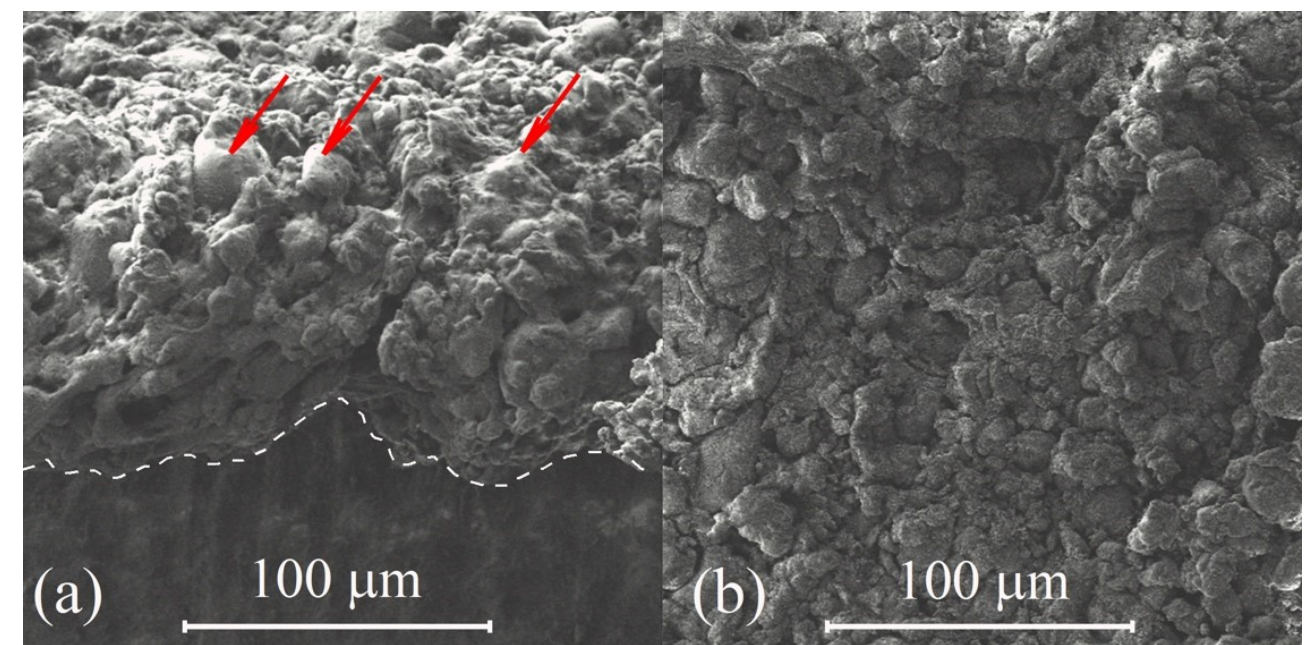

Fig. 13 SEM images of the deposited F5A and coating at $5 \mathrm{mms}$ and $573 \mathrm{~K}$; (a) Side view image; (b) Top view image. Arrows indicate exposed peaks of Al substrate.

Fig. 14 (a-c) show the deposition efficiency measured for $10 \mu \mathrm{m}$ as-received FEP particles for different gas temperatures, traverse speeds and pass number. Deposition efficiency increases with increasing traverse speed and gas temperature at low pass number. Since the adhesion of particle on the substrate is mainly determined by the thin melted layer of FEP as discussed previously, increasing pass number may affect the initially deposited FEP layers. It suggests that the initiation of the thin melted layer is important for the initial deposition of the particles. Continuous cold-spraying onto the substrate removed the loosely deposited layer or particle from the roughened substrate surface as the adhesion at the interface is weak and unstable. Increasing the substrate temperature or the gas temperature may result in a high deposited weight to sprayed weight ratio but formed layer/coating may turn out to be thin and inconsistent. Continuous shearing of the initially deposited particles/layers by the impinging gas and particles is considered to contribute to this problem. Increasing the pass number from 2-pass to 4-pass, however, does not show a similar effect. The possible reason for this is the adhesion between particle and substrate, which is the melted layer, could only withstand the 
weight of the particles/layers up to a certain limit before the deposited weight of the accumulated particles/layers became too heavy and subsequently removed by the impinging gas and particle. At this point, the accumulation of melted layers/particles occurred mainly between the substrate peaks.

Besides, the continuous succession of impacts by the particles could severely deform the surface of the Al substrate, to an extent where a slight erosion was observed. This trend was only observed in Fig. 14(a) for 16-pass at $773 \mathrm{~K}$. The erosion may have occurred at the edge of the substrate where the severely deformed substrate edges were chipped off as a result of a continuous succession impacts from the particles because A1100 is soft and ductile.

A comparison of the deposition efficiency as the function of pass number at $573 \mathrm{~K}$ and $773 \mathrm{~K}$ for FEP, F5S and F5A, is described in Fig. 15(a) and (b). Here, the F5A showed the highest deposition efficiency in both gas temperature and different pass number. These results were obtained under identical traverse speed of $5 \mathrm{~mm} / \mathrm{s}$ for all three feedstocks. At $573 \mathrm{~K}$, the measured deposition efficiency of F5A on the Al substrate exceeded more than three-fold compared to the FEP and F5S. The value decreased with increasing pass number. On the other hand, a similar trend was observed at a higher gas temperature of $773 \mathrm{~K}$. Despite this, the measured deposition efficiency is reduced for FEP, F5S and F5A.

These results suggest two possible reasons for the trend: (1) adhesion mechanisms for FEP, F5S and F5A was governed mainly by the initially melted layer; and (2) FNA is important in the coating build-up process. The first point has been explained in detail and discussed throughout this paper. From the deposition behaviour of a single particle of an as-received FEP particle on the Al substrate, the interface of the deformed particle was found to be entirely or partially melted. Similarly, a deposited F5A particle, either severely or partially deformed upon impact, adhered well to the melted layers covered in nano-particles (FNA). The scattered nanoparticles from the F5A particles may come as a product of multiple impacts occurred on the 
substrate and/or particle-to-particle interaction upon impact. In other words, a finely distributed FNA network on the melted layer may enhance the adhesion of the FEP particle to a certain extent from the anchoring effect at the particle/substrate interface, albeit reasonably weak. In addition, the role of a chemical bond especially hydroxyl group was also considered. Regardless, the possibility of a strong adhesion from the hydroxyl group in this case may not be possible due to small traces of hydroxyl group on the surface treated FNA and on the chemical structure of the FEP itself. The second point has been mentioned in the preceding paragraphs and other studies (Ref 23,24,27,30,37). FNA enhanced coating build-up process occurred rapidly and in a quick succession of particles which offsets the adhesion limit of the melted layer and FNA. As a result, delamination occurs as the coating gets thicker/heavier. In contrast to FNA, a coating thickness of less than $5.0 \mu \mathrm{m}$ was observed in cold-sprayed samples using F5S. Distribution behaviour of FNC on the FEP particle may be the deciding factor. In comparison to a finely distributed network of FNA, sparsely distributed agglomerated FNS on the FEP particle surface showed a less significant effect on interfacial adhesion upon impact. In the perspective of surface charge, similar surface charges between FNS and FEP may results in repulsive force compared to oppositely charged surface between FNA and FEP. The combination of surface charge and distribution behaviour may influence the adhesion strength.

The overall DE for FEP particle is comparatively lower $(0.11 \%)$ than F5A $(0.16 \%)$, but FEP (0.11\%) showed higher DE than F5S (0.04\%) under optimized spray condition. Although this result suggests the addition of FNA to the FEP yields a better DE, more work needed to increase the DE, coating thickness and adhesion for its practical use. 

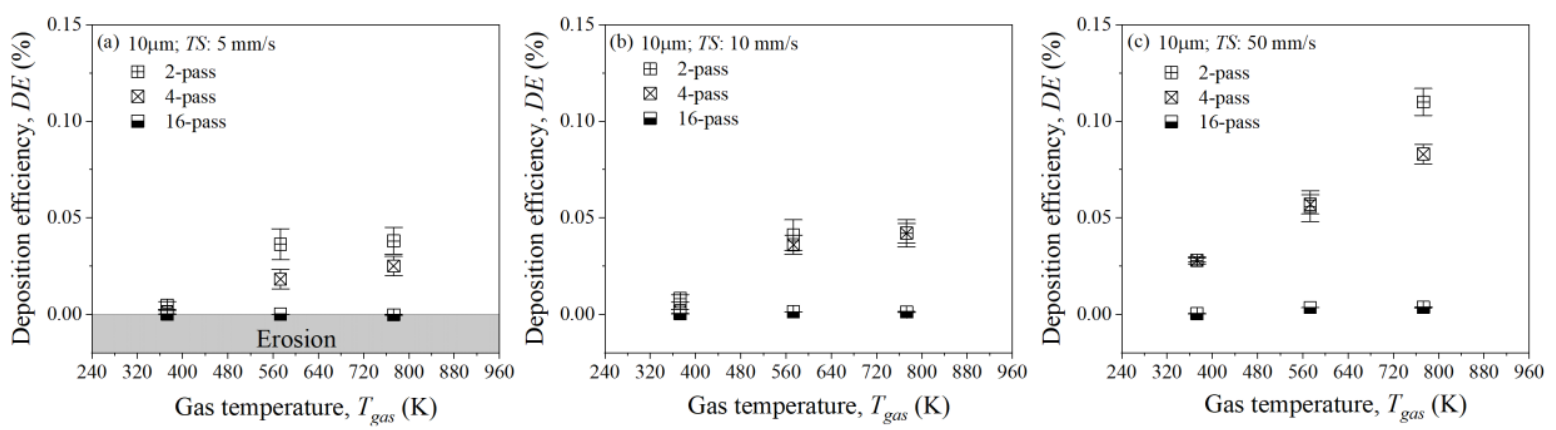

Fig. 14 Deposition efficiency of $10 \mu \mathrm{m}$ FEP for different pass number as a function of the gas temperature, at traverse speed of (a) $5 \mathrm{~mm} / \mathrm{s}$; (b) $10 \mathrm{~mm} / \mathrm{s}$; and (c) $50 \mathrm{~mm} / \mathrm{s}$.
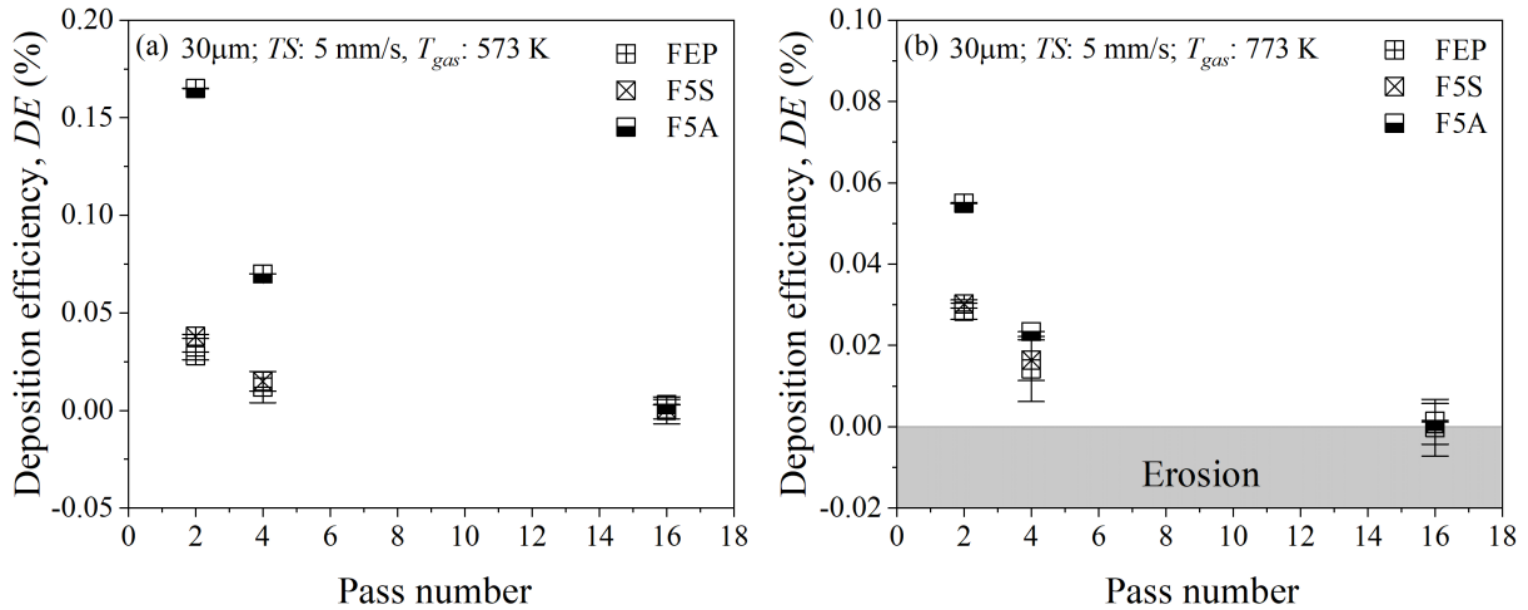

Fig. 15 Deposition efficiency of FEP, F5S and F5A as a function of pass number for gas temperature of (a) $573 \mathrm{~K}$; and (b) $773 \mathrm{~K}$.

3.3 Substrate temperature and particle velocity.

Substrate temperature and particle velocity play an important role in the coating up and adhesion. Using a thermal camera and Hi-Watch system, the substrate temperature and the particle velocity have been recorded and the results are described in Fig. 16. The measured A1 substrate temperature for all cold-spray conditions showed a much lower temperature range than the gas temperature ( Fig. 16(a)). Thus, when the particle impacting the substrate during cold-spray, temperature gradient at the interface of the powder and the substrate is expected 
due to different thermal history of the materials. Simultaneously, the particle velocity of a $30 \mu \mathrm{m}$ particle in this gas temperature range is described in Fig. 16(b). Other studies (Ref $22,25)$ suggested the minimum particle impact velocity in the range of $100-270 \mathrm{~m} / \mathrm{s}$ for a highly crystalline $48 \mu \mathrm{m}$ particle high-density polyethylene (HDPE) on a like-on-like deposition at given particle initial temperature of $15^{\circ} \mathrm{C}$ to $25^{\circ} \mathrm{C}$, and nozzle stand-off distance of 10 - $20 \mathrm{~mm}$. Similar results were also reported (Ref 21,26) for HDPE-to-Al deposition. However, in this work, a slightly higher in-flight particle velocity in the subsonic region of $300 \mathrm{~m} / \mathrm{s}$ was measured for the $30 \mu \mathrm{m}$ FEP particle even at RT gas temperature. The relationship between particle velocity and inlet gas temperature is reported in Fig. 16(b). The in-flight particle velocity increased gradually and reached a maximum limit below than $400 \mathrm{~m} / \mathrm{s}$. The in-flight particle temperature was not measured as it was difficult to perform. However, an ongoing study on the thermal gradient of a polymeric particle in cold-spray is being conducted within our research group. These results indicate that increasing substrate temperature would facilitate in the deposition of melted layer and subsequent coating build-up. It has previously been found that the optimal spray condition was obtained with an inlet gas temperature and pressure of $573 \mathrm{~K}$ to $773 \mathrm{~K}$ and $0.5 \mathrm{MPa}$, leading to a substrate temperature of $310 \mathrm{~K}$ to $332.3 \mathrm{~K}$ and particle velocity of $332 \mathrm{~m} / \mathrm{s}$ to $355 \mathrm{~m} / \mathrm{s}$. Similarly, higher particle velocity imparts plastic deformation on particle upon impact, resulting in localized temperature rise necessary for particle deposition on the Al substrate. 

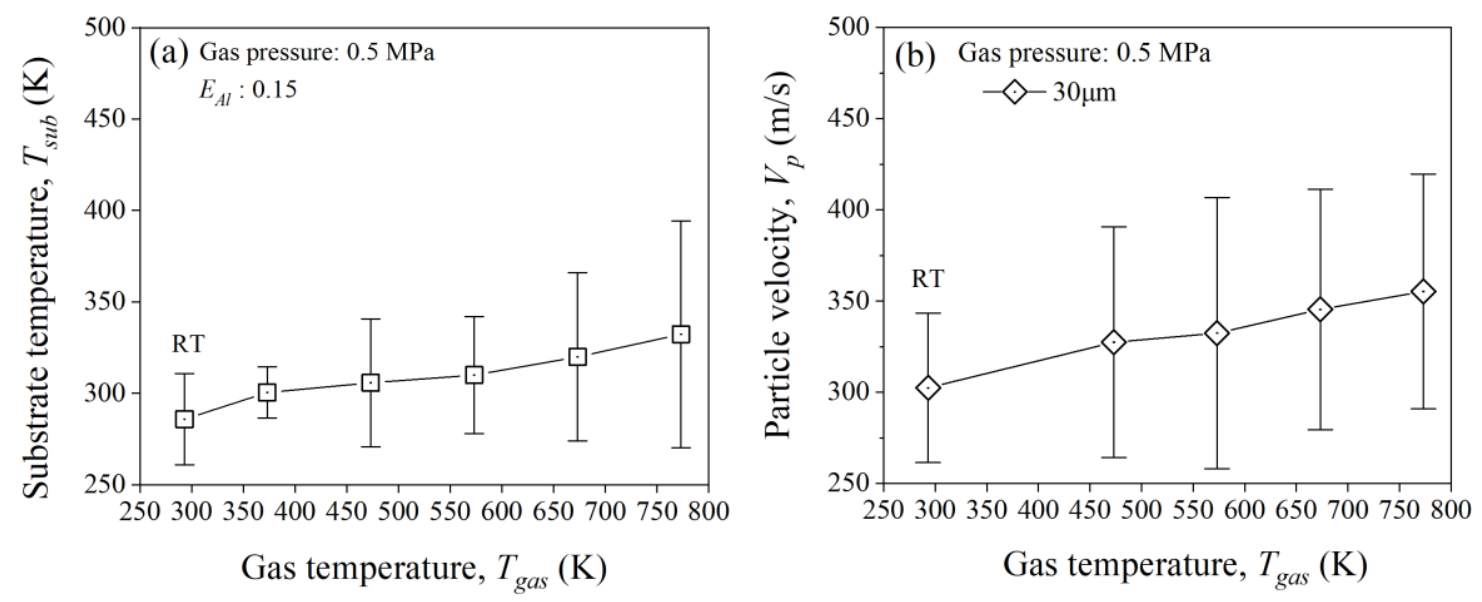

Fig. 16 (a) Relationship between the substrate surface as a function of the inlet gas temperature measured by a thermal image camera; and (b) relationship between the particle velocity as a function of the inlet gas temperature. Both results are taken using $30 \mu \mathrm{m}$ FEP particles at $0.5 \mathrm{MPa}$ gas pressure.

\subsection{Characterization of the wetting behaviour}

Dynamic angle measurement was performed using a $10 \pm 0.5 \mu \mathrm{L}$ water droplet on the coldsprayed samples to evaluate the wettability behaviour of the coating. Wettability properties can be interpreted in many standpoints, but we focused ours on the hydrophobicity and water repellency of the coating. One to the main objectives of this work is to develop a robust superhydrophobic and self-cleaning fluoropolymer coating using low-pressure cold spray technique. Thus, a combination of hydrophobic and a relatively low roll-off angle surface is required. A surface is presumed superhydrophobic when the static contact angle is more than $150^{\circ}$ and roll-off angle is lower than $10^{\circ}$ (Ref 63). On a cold-sprayed Al surface, hydrophobization is achieved by depositing a hydrophobic polymer layer on the surface. In our work, as mentioned in preceding sections, we attempted a solid-state deposition of the asreceived FEP and FNC mixed F5S/F5A particles using a low-pressure cold spray on an A1100 
substrate. A thin layer of coating was formed. For this purpose, only a selection of the best cold-sprayed samples was evaluated.

For FEP coatings obtained in different cold-spray gas temperature, the results are reported in Fig. 17(a) for data obtained using $10 \mu \mathrm{m} \mathrm{FEP} \mathrm{particles} \mathrm{cold-sprayed} \mathrm{at} 50 \mathrm{~mm} / \mathrm{s}$ for 2-pass. The coating thickness was less than $5 \mu \mathrm{m}$ for all samples. The results indicate that the highest rolloff angle, more than $90^{\circ}$, was measured for the non-cold-sprayed Al substrate sample. For coldsprayed samples, the roll-off angle is seen to be decreased slightly with increasing temperature, however, no distinguishable difference observed. Roll-off angle and hysteresis angle for these samples were measured below $7^{\circ}$ and $2^{\circ}$, respectively. This suggests that low roll-off angle can be achieved with thin coating regardless of the cold-spray gas temperature

Fig. 17(b) describes the comparison in roll-off angle and hysteresis angle between the coldsprayed coatings and a commercially available thin Teflon film (thickness of $100 \mu \mathrm{m}$ ). The measured coating thickness for F5S was less than $5 \mu \mathrm{m}$, whereas, a thicker coating was measured for F5A. The addition of FNC results in excellent water-repellency for the coldsprayed coating including low roll-off angle and hysteresis angle for both F5S and F5A compared to the Teflon film. This indicates high wettability or hydrophilic properties for the as-received Al substrate surface. On the other hand, a roll-off angle of $15^{\circ} \pm 6.2^{\circ}$ was measured for the thin Teflon film. A comparatively low roll-off angle (less than $10^{\circ}$ ) was measured for all as-received FEP cold-sprayed surface, including F5S and F5A samples. The lowest roll-off angle value was measured in F5A coating $\left(4.2 \pm 2.5^{\circ}\right)$ cold-sprayed at $573 \mathrm{~K}, 0.5 \mathrm{MPa}$, and for a traverse speed of $5 \mathrm{~mm} / \mathrm{s}$. A higher value of roll-off angle $\left(6.2 \pm 3.7^{\circ}\right)$ was measured for the surface cold-sprayed with F5S particles under similar spray condition with F5A. All coldsprayed samples exhibit low hysteresis angle of less than $2^{\circ}$. The results indicate that the addition of FNC does not affect FEP hydrophobic properties after cold-sprayed. On the other hand, the addition of FNA indicates a better roll-off angle for the resultant coating. The 
incorporation of these nano-sized particles onto the coating surface enhance the water repellency of the coating from the topographical advantages which favour the entrainment of air cushion underneath the droplet (Cassie-state). It indicates the importance of topography of the surface with regards to its hydrophobicity.

Overall, the above suggests that the resultant layer of cold-sprayed deposited FEP layer on the Al substrate surface demonstrated excellent water repellency which is suitable for self-cleaning properties. The combination of outstanding thermal and physical properties of the FEP and excellent water-repellency and hydrophobicity of both FEP and FNC provides a useful material candidate for a self-cleaning coating.
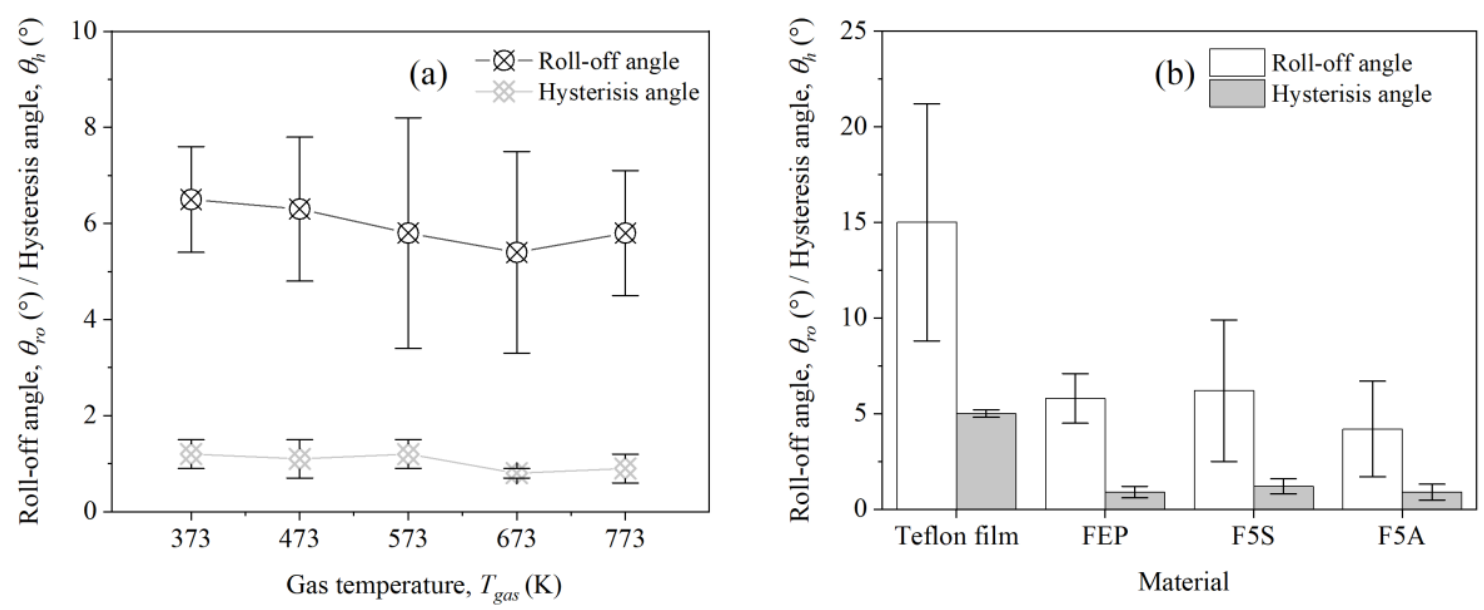

Fig. 17 Droplet roll-off angle and hysteresis angle measured using a dynamic contact angle measurement of (a) Al substrate cold-sprayed with FEP at different gas temperature; and (b) a comparison between a thin Teflon film and the optimal DE samples of Al substrate coldsprayed with FEP, F5S, F5A.

\section{Conclusion}

Fluoropolymers, such as fluoroethylene propylene (FEP), are known to exhibit excellent water repellency properties. However, because of their hyperelastic behaviour, they are difficult to 
manufacture. In this study, we successfully performed FEP hydrophobic coating on aluminum substrate using cold-spray process.

Analysis of the deposition mechanisms of the FEP on the aluminum substrate was carried out at a different gas temperature, traverse speed and particle size. By reducing the particle size and increasing the temperature of the gas and the substrate surface, increase of the deposition efficiency was observed. The melted layer formed by the deposited particle, as a result of the localized heat upon impact, provide a critical surface for interfacial adhesion. However, this melted layer in form of a splat or filament-like structure provides a weak adhesion force, especially with the offset of a heavier thick coating leading to its delamination. To increase the deposition efficiency and strengthen the interface polymer/substrate, $5 \%$ of hydrophobized fumed nano-ceramics were added to the polymer feedstock. Differences in deposition behaviour were observed between fumed nano-silica (FNS) and fumed nano-alumina (FNA) driven by the difference in surface charges between the nano-particles and the FEP particles. Thus, while attractive force allows a homogeneous repartition of FNA on the FEP particle, negative force leads to the formation of FNS agglomerates on the FEP particles. The addition of the hydrophobized fumed nano-ceramics enhanced the hydrophobic properties of FEP, such as the coating shows higher water repellency properties than commercially available Teflon film.

Despite this, the deposition efficiency and adhesion strength of the resultant coating remains a challenge for practical use. Hence, further studies are being formulated to approach this problem systematically and thoroughly. This work is intended to gauge the feasibility of coating fluoropolymer by cold-spray. In other words, it is the initial step of a larger study. Hence, further studies on improvement of interfacial adhesion strength (initial layer) are currently being carried out. 
Acknowledgement

Authors would like to acknowledge Japan Society for the Promotion of Science (JSPS) Kakenhi, for the financial assistance throughout the work (Grant-in-Aid for Scientific Research(A)17H01235). We extended our acknowledgement to Nippon Aerosil Co. (NAC) for providing the fumed nano-alumina, including Iwate Industrial Research Institute, Dr. Nicolas Mary and Mr Katsumi Ito, for their assistance and invaluable guidance.

References

1. E. Dhanumalayan and G.M. Joshi, Performance Properties and Applications of Polytetrafluoroethylene (PTFE)-a Review, Adv. Compos. Hybrid Mater., 2018, 1(2), p 247-268, doi:10.1007/s42114-018-0023-8.

2. T.R. Dargaville, G.A. George, D.J.T. Hill, and A.K. Whittaker, An Investigation of the Thermal and Tensile Properties of PFA Following $\gamma$-Radiolysis, Macromolecules, 2003, 36(19), p 7132-7137, doi:10.1021/ma0302309.

3. J. Gardiner, Fluoropolymers: Origin, Production, and Industrial and Commercial Applications, Aust. J. Chem., 2015, 68(1), p 13-22.

4. N.S. Bhairamadgi, S.P. Pujari, C.J.M. Van Rijn, and H. Zuilhof, Adhesion and Friction Properties of Fluoropolymer Brushes: On the Tribological Inertness of Fluorine, Langmuir, 2014, 30(42), p 12532-12540.

5. H. Teng, Overview of the Development of the Fluoropolymer Industry, Appl. Sci., 2012, 2(2), p 496-512, doi:10.3390/app2020496.

6. Y. Ohkubo, K. Ishihara, M. Shibahara, A. Nagatani, K. Honda, K. Endo, and K. Yamamura, Drastic Improvement in Adhesion Property of Polytetrafluoroethylene (PTFE) via Heat-Assisted Plasma Treatment Using a Heater, Sci. Rep., 2017, 7(1), p 19, doi:10.1038/s41598-017-09901-y.

7. I. Mathieson, D.M. Brewis, I. Sutherland, and R.A. Cayless, Pretreatments of 
Fluoropolymers, J. Adhes., 1994, 46(1-4), p 49-56.

8. V. Champagne, D. Helfritch, P. Leyman, R. Lempicki, and S. Grendahl, The Effects of Gas and Metal Characteristics on Sprayed Metal Coatings, Modell. Simul. Mater. Sci. Eng., 2005, 13(7), p 1119-1128.

9. S. Grigoriev, A. Okunkova, A. Sova, P. Bertrand, and I. Smurov, Cold Spraying: From Process Fundamentals towards Advanced Applications, Surf. Coat. Technol., 2015, 268, p 77-84, doi:10.1016/j.surfcoat.2014.09.060.

10. A. Papyrin; V. Kosarev; S. Klinkov; A. Alkhimov; and V.M. Fomin; "Cold Spray Technology," Elsevier, 2007.

11. K. Ogawa, K. Ito, K. Ichimura, Y. Ichikawa, S. Ohno, and N. Onda, Characterization of Low-Pressure Cold-Sprayed Aluminum Coatings, J. Therm. Spray Technol., 2008, 17, p $728-735$.

12. Y. Ichikawa and K. Ogawa, Effect of Substrate Surface Oxide Film Thickness on Deposition Behavior and Deposition Efficiency in the Cold Spray Process, J. Therm. Spray Technol., 2015, 24, p 1269-1276.

13. Y. Ichikawa and $\bullet$ Kazuhiro Ogawa, Critical Deposition Condition of CoNiCrAlY Cold Spray Based on Particle Deformation Behavior, J. Therm. Spray Technol., 2017, 26, p 340-349, doi:10.1007/s11666-016-0477-6.

14. Y. Ichikawa, R. Tokoro, M. Tanno, and K. Ogawa, Elucidation of Cold-Spray Deposition Mechanism by Auger Electron Spectroscopic Evaluation of Bonding Interface Oxide Film, Acta Mater., 2019, 164, p 39-49.

15. M.F. Smith, Comparing Cold Spray with Thermal Spray Coating Technologies, The Cold Spray Materials Deposition Process: Fundamentals and Applications, V.K. Champagne, Ed., Woodhead Publishing Limited, 2007, p 43-61.

16. J.D. Majumdar, "Handbook of Manufacturing Engineering and Technology," Handbook 
of Manufacturing Engineering and Technology, Springer-Verlag, 2013.

17. H. Assadi, T. Schmidt, H. Richter, J.O. Kliemann, K. Binder, F. Gärtner, T. Klassen, and H. Kreye, On Parameter Selection in Cold Spraying, J. Therm. Spray Technol., 2011, 20(6), p 1161-1176.

18. T. Hussain, D.G. McCartney, P.H. Shipway, and D. Zhang, Bonding Mechanisms in Cold Spraying: The Contributions of Metallurgical and Mechanical Components, $J$. Therm. Spray Technol., 2009, 18(3), p 364-379.

19. D. Macdonald, R. Fernández, F. Delloro, and B. Jodoin, Cold Spraying of Armstrong Process Titanium Powder for Additive Manufacturing, J. Therm. Spray Technol., 2017, 26, p 598-609.

20. Y. Xu and I.M. Hutchings, Cold Spray Deposition of Thermoplastic Powder, Surf. Coat. Technol., 2006, 201(6), p 3044-3050.

21. A.S. Alhulaifi, G.A. Buck, and W.J. Arbegast, Numerical and Experimental Investigation of Cold Spray Gas Dynamic Effects for Polymer Coating, J. Therm. Spray Technol., 2012, 21(5), p 852-862, doi:10.1007/s11666-012-9743-4.

22. Z. Khalkhali and J.P. Rothstein, Characterization of the Cold Spray Deposition of a Wide Variety of Polymeric Powders, Surf. Coat. Technol., 2020, 383.

23. K. Ravi, Y. Ichikawa, T. Deplancke, K. Ogawa, O. Lame, and J.Y. Cavaille, Development of Ultra-High Molecular Weight Polyethylene (UHMWPE) Coating by Cold Spray Technique, J. Therm. Spray Technol., 2015, 24(6), p 1015-1025.

24. K. Ravi, Y. Ichikawa, K. Ogawa, T. Deplancke, O. Lame, and J.Y. Cavaille, Mechanistic Study and Characterization of Cold-Sprayed Ultra-High Molecular Weight Polyethylene-Nano-Ceramic Composite Coating, J. Therm. Spray Technol., 2016, 25(12), p 160-169.

25. T.B. Bush, Z. Khalkhali, • Victor Champagne, • David, P. Schmidt, and J.P. Rothstein, 
Optimization of Cold Spray Deposition of High-Density Polyethylene Powders, $J$. Therm. Spray Technol., 2017, 26, p 1548-1564, doi:10.1007/s11666-017-0627-5.

26. S. Shah, J. Lee, and J.P. Rothstein, Numerical Simulations of the High-Velocity Impact of a Single Polymer Particle During Cold-Spray Deposition, J. Therm. Spray Technol., 2017, 26(5), p 970-984.

27. K. Ravi, T. Deplancke, K. Ogawa, J.Y. Cavaillé, and O. Lame, Understanding Deposition Mechanism in Cold Sprayed Ultra High Molecular Weight Polyethylene Coatings on Metals by Isolated Particle Deposition Method, Addit. Manuf., 2018, 21(March 2017), p 191-200, doi:10.1016/j.addma.2018.02.022.

28. K. Ravi, T. Deplancke, O. Lame, K. Ogawa, J.-Y. Cavaillé, and F. Dalmas, Influence of Nanoceramic Interlayer on Polymer Consolidation during Cold-Spray Coating Formation, J. Mater. Process. Technol., 2019, p 116254, doi:10.1016/J.JMATPROTEC.2019.116254

29. W. Tillmann and J.F. Zajaczkowski, Investigation of Low-Pressure Cold-Gas Dynamic Spraying of Polyamide-12 (PA12) on Steel Surfaces, IOP Conf. Ser.: Mater. Sci. Eng., 2019, 480(1).

30. W. Lock Sulen, K. Ravi, C. Bernard, N. Mary, Y. Ichikawa, and K. Ogawa, Effects of Nano-Ceramic Particle Addition for Cold Sprayed Fluoropolymer Coatings, Key Eng. Mater., 2019, 813 KEM, p 141-146.

31. A. Alkhimov, A. Papyrin, and V. Kosarev, Gas-dynamic spraying method for applying a coating, US Patent 5,302,414, 1994.

32. V. Gillet, E. Aubignat, S. Costil, B. Courant, C. Langlade, P. Casari, W. Knapp, and M.P. Planche, Development of Low Pressure Cold Sprayed Copper Coatings on Carbon Fiber Reinforced Polymer (CFRP), Surf. Coat. Technol., 2019, 364(November 2018), p 306-316, doi:10.1016/j.surfcoat.2019.01.011. 
33. G. Yang, W. Xie, M. Huang, V.K. Champagne, J.H. Lee, J. Klier, and J.D. Schiffman, Polymer Particles with a Low Glass Transition Temperature Containing Thermoset Resin Enable Powder Coatings at Room Temperature, Ind. Eng. Chem. Res., 2019, 58(2), p 908-916.

34. E.D. Zanotto and J.C. Mauro, The Glassy State of Matter: Its Definition and Ultimate Fate, J. Non-Cryst. Solids, 2017, 471(April), p 490-495.

35. L.H. Sperling, "Introduction to Physical Polymer Science: Fourth Edition," Introduction to Physical Polymer Science: Fourth Edition, Wiley, 2005.

36. R.N. Raoelison, C. Verdy, and H. Liao, Cold Gas Dynamic Spray Additive Manufacturing Today: Deposit Possibilities, Technological Solutions and Viable Applications, Mater. Des., 2017, 133, p 266-287, doi:10.1016/J.MATDES.2017.07.067.

37. K. Ravi, W.L. Sulen, C. Bernard, Y. Ichikawa, and K. Ogawa, Fabrication of Micro/Nano-Structured Super-Hydrophobic Fluorinated Polymer Coatings by Cold-Spray, Surf. Coat. Technol., 2019, 373, p 17-24.

38. A. Gibas, A. Baszczuk, M. Jasiorski, and M. Winnicki, Prospects of Low-Pressure Cold Spray for Superhydrophobic Coatings, Coatings, 2019, 9(12), p 829, doi:10.3390/coatings9120829.

39. The Chemours Company, "Teflon ${ }^{\mathrm{TM}}$ Industrial Coatings: Fluorinated Ethylene Propylene," 2020, https://www.teflon.com/en/products/coatings/fep-coatings. Accessed 11 April 2020.

40. DuPont, "Teflon $\quad$ FEP 4100," $\quad$ (U.S.A.), http://www.rjchase.com/fep_handbook.pdf. Accessed 15 May 2019.

41. G. Wypych, "Handbook of Polymers: Second Edition," Handbook of Polymers: Second Edition, ChemTec Publishing, 2016. 
42. Evonik Industries, "Fumed Silica Technical Overview," 2015, p 1-104, https://www.aerosil.com/sites/lists/re/documentssi/ti-1283-aeroxide-and-aerosil-inlighting-applications-en.pdf. Accessed 15 July 2019.

43. Evonik Industries, “AEROXIDE®-Fumed Metal Oxides," 2017, p 1-84, https://www.aerosil.com/product/aerosil/downloads/to-aeroxide-en.pdf. Accessed 16 November 2018.

44. A.S. Dukhin and P.J. Goetz, "Characterization of Liquids, Dispersions, Emulsions, and Porous Materials Using Ultrasound," Characterization of Liquids, Dispersions, Emulsions, and Porous Materials Using Ultrasound, Elsevier, 2017.

45. Ing. Christian Oetzel, "PARTICLE," 3P Instruments Particle World, 2018, https://www.3p-instruments.com/wp-content/uploads/2018/05/PARTICLE-WORLD19.pdf. Accessed 2 April 2020.

46. V. Villani and R. Pucciariello, Thermal Properties at Room Temperature of Polytetrafluoroethylene, J. Therm. Anal., 1991, 37(8), p 1759-1766.

47. R. Pucciariello and V. Villani, Melting and Crystallization Behavior of Poly(Tetrafluoroethylene) by Temperature Modulated Calorimetry, Polymer (Guildf)., 2004, 45(6), p 2031-2039.

48. M.C. Righetti, A. Boggioni, M. Laus, D. Antonioli, K. Sparnacci, and L. Boarino, Thermal and Mechanical Properties of PES/PTFE Composites and Nanocomposites, $J$. Appl. Polym. Sci., 2013, 130(5), p 3624-3633.

49. P. Fauchais and M. Vardelle, Sensors in Spray Processes, J. Therm. Spray Technol, 2010, 19(4), p 668-694.

50. C.-D. Wen and I. Mudawar, "Experimental Investigation of Emissivity of Aluminum Alloys and Temperature Determination Using Multispectral Radiation Thermometry (MRT) Algorithms," 2010 14th International Heat Transfer Conference, ASME, Ed., 
Aug 8-13 (Washington, DC), ASME, 2002, p 551-562.

51. L. Gao and T.J. McCarthy, "Contact Angle Hysteresis Explained,” Langmuir, 2006, p $6234-6237$.

52. S. Lee, J.S. Park, and T.R. Lee, The Wettability of Fluoropolymer Surfaces: Influence of Surface Dipoles, Langmuir, American Chemical Society, 2008, 24(9), p 4817-4826, doi:10.1021/la700902h.

53. M. Ruan, Y. Zhan, Y. Wu, X. Wang, W. Li, Y. Chen, M. Wei, X. Wang, and X. Deng, Preparation of PTFE/PDMS Superhydrophobic Coating and Its Anti-Icing Performance, RSC Adv., 2017, 7, p 41339-41344.

54. S. Das, S. Kumar, S.K. Samal, S. Mohanty, and S.K. Nayak, A Review on Superhydrophobic Polymer Nanocoatings: Recent Development and Applications, Ind. Eng. Chem. Res., 2018, 57(8), p 2727-2745.

55. R.J. HUNTER, Electroviscous and Viscoelectric Effects, Zeta Potential in Colloid Science, United Sta, ACADEMIC PRESS LIMITED, 1981, p 179-218, doi:10.1016/b978-0-12-361961-7.50009-2.

56. V.M. Gun'ko, I.F. Mironyuk, V.I. Zarko, E.F. Voronin, V. V. Turov, E.M. Pakhlov, E. V. Goncharuk, Y.M. Nychiporuk, N.N. Vlasova, P.P. Gorbik, O.A. Mishchuk, A.A. Chuiko, T. V. Kulik, B.B. Palyanytsya, S. V. Pakhovchishin, J. Skubiszewska-Zięba, W. Janusz, A. V. Turov, and R. Leboda, Morphology and Surface Properties of Fumed Silicas, J. Colloid Interface Sci., 2005, 289(2), p 427-445.

57. Chereches and Minea, Electrical Conductivity of New Nanoparticle Enhanced Fluids: An Experimental Study, Nanomaterials, 2019, 9(9), p 1228.

58. M. Kotrba and L.-H. Schilling, Measurement of PH in Ethanol, Distilled Water, and Their Mixtures: On the Assessment of PH in Ethanol-Based Natural History Wet Collections and the Detrimental Aspects of Dilution with Distilled Water, Collect. 
Forum, 2017, 31(1-2), p 84-101.

59. G.V. Gusev, Methods of Investigation: Hermans-Weidinger X-Ray Diffraction Technique for Determining Polymer Crystallinity and the Use of Ruland Ratio, Polym. Sci. USSR, 1977, 20, p 1295-1297, doi:10.1016/0032-3950(78)90270-8.

60. K.A. Moly, H.J. Radusch, R. Androsh, S.S. Bhagawan, and S. Thomas, Nonisothermal Crystallisation, Melting Behavior and Wide Angle X-Ray Scattering Investigations on Linear Low Density Polyethylene (LLDPE)/Ethylene Vinyl Acetate (EVA) Blends: Effects of Compatibilisation and Dynamic Crosslinking, Eur. Polym. J., 2005, 41, p 1410-1419, doi:10.1016/j.eurpolymj.2004.10.016.

61. H. Che, P. Vo, and S. Yue, Investigation of Cold Spray on Polymers by Single Particle Impact Experiments, J. Therm. Spray Technol., 2019, 28(1-2), p 135-143.

62. K.H. Kim, Z. Akase, T. Suzuki, and D. Shindo, Charging Effects on SEM/SIM Contrast of Meta1/Insulator System in Various Metallic Coating Conditions, Mater. Trans., 2010, 51(6), p 1080-1083.

63. M. Paven, L. Mammen, and D. Vollmer, "Challenges and Opportunities of Superhydrophobic/Superamphiphobic Coatings in Real Applications," RSC Smart Mater., Royal Society, 2016, doi:10.1039/9781782622192-00209. 
Fig. 1 Schematic representation of nozzle used in this study.

Fig. 2 SEM images of (a) as-received pure FEP particles, (b) F5S, and (c) F5A. Flocculants (marked by arrows) evident in F5S in contrast to finely dispersed FNA (marked by arrows) in F5A.

Fig. 3 EDX line scan results of (a) F5S; and (b) F5A. Scanning direction (as indicated by arrow) was performed along the scanning line (yellow line).

Fig. 4 Relationship between zeta potential in function of the solution $\mathrm{pH}$ for the FEP, and hydrophobized FNS and FNA (also shown in the inset). For each particle, the isoelectric point (IEP) is identified.

Fig. 5 X-ray diffractogram of (a) as-received FEP particles of different mean sizes 10, 30 and $100 \mu \mathrm{m}$. (b) Deconvolution of the X-ray diffractogram and identification of the degree of crystallinity for the three mean-size of FEP particle studied.

Fig. 6 DSC results for FEP particles The glass transition temperature, $T_{g}$, is marked by an endothermic deviation of the heat flow and the melting temperature, $T_{m}$, is characterized by an endothermic peak.

Fig. 7 Mean roughness, $R_{a}$ and the maximum height, $R_{z}$, of cold-sprayed A1100 substrate in the function of pass numbers for (a-b)10 $\mu \mathrm{m}$, (c-d) $30 \mu \mathrm{m}$, and (e-f) $100 \mu \mathrm{m}$.

Fig. 8 Gap at the particle-substrate interface indicating a weak adhesion of the pure FEP particle after impact at (a) $373 \mathrm{~K}$; and (b) $573 \mathrm{~K}$ for a traverse speed of $50 \mathrm{~mm} / \mathrm{s}$ Arrows in (a) indicate gap at the particle-substrate interface; Arrows in (b) indicate filament-like structure holding the deposited particle onto the substrate surface. 
Fig. 9 SEM images of the deposited F5A particles at gas temperature of $573 \mathrm{~K}$, gas pressure of 0.5 MPa and traverse speed of $50 \mathrm{~mm} / \mathrm{s}$ for (a) Partially melted; and ( b) melted and deformed. Bright area indicates Al substrate without melted layer and arrows indicate finely dispersed FNA on melted FEP layer.

Fig. 10 SEM images of deposited as-received FEP particles on Al substrate at a traverse speed of $50 \mathrm{~mm} / \mathrm{s}$ and gas temperature of $373 \mathrm{~K}$. Arrows indicate melted layer from the deposited particle.

Fig. 11 Tilted SEM images of as-received FEP particle at (a) 2-pass and (b) 4-pass performed at a gas temperature of $773 \mathrm{~K}$ and a traverse speed of $5 \mathrm{~mm} / \mathrm{s}$.

Fig. 12 SEM images of the cold-sprayed Al substrate surface in (a) 2-pass; and (b) 16-pass for $30 \mu \mathrm{m}$ of as-received FEP particles, performed at $5 \mathrm{~mm} / \mathrm{s}$ and $773 \mathrm{~K}$. Deposited layer of particles are indicated by the bright colour from the material charge-up.

Fig. 13 SEM images of the deposited F5A and coating at $5 \mathrm{mms}$ and $573 \mathrm{~K}$; (a) Side view image; (b) Top view image. Arrows indicate exposed peaks of Al substrate.

Fig. 14 Deposition efficiency of $10 \mu \mathrm{m}$ FEP for different pass number as a function of the gas temperature, at traverse speed of (a) $5 \mathrm{~mm} / \mathrm{s}$; (b) $10 \mathrm{~mm} / \mathrm{s}$; and (c) $50 \mathrm{~mm} / \mathrm{s}$.

Fig. 15 Deposition efficiency of FEP, F5S and F5A as a function of pass number for gas temperature of (a) $573 \mathrm{~K}$; and (b) $773 \mathrm{~K}$.

Fig. 16 (a) Relationship between the substrate surface as a function of the inlet gas temperature measured by a thermal image camera; and (b) relationship between the particle velocity as a function of the inlet gas temperature. Both results are taken using $30 \mu \mathrm{m}$ FEP particles at $0.5 \mathrm{MPa}$ gas pressure.

Fig. 17 Droplet roll-off angle and hysteresis angle measured using a dynamic contact angle measurement of (a) Al substrate cold-sprayed with FEP at different gas temperature; and (b) a 
comparison between a thin Teflon film and the optimal DE samples of Al substrate coldsprayed with FEP, F5S, F5A.

Table 1 Mechanical and physical properties of the semi-crystalline fluoroethylene propylene used in this study.

\begin{tabular}{lcc}
\hline Parameter & Unit & Value \\
\hline Density at $20^{\circ} \mathrm{C}(\operatorname{Ref} 40)$ & $\mathrm{g} / \mathrm{cm}^{3}$ & $2.12-2.17$ \\
Melting point (Ref 40) & $\mathrm{K}$ & $576-586$ \\
Heat of fusion (DSC) (Ref 40) & $\mathrm{J} / \mathrm{g}$ & 9.8 \\
Crystallinity (Ref 41) & $\%$ & $40-70$ \\
Glass transition temperature (Ref 41) & $\mathrm{K}$ & 353.2 \\
\hline
\end{tabular}

Table 2 Material properties of hydrophobic fumed nano-ceramics (Ref 36,37).

\begin{tabular}{lccc}
\hline Parameter & Unit & \multicolumn{2}{c}{ Value } \\
\hline Grade & & $\mathrm{R} 805$ & Alu C805 \\
Primary size & $\mathrm{nm}$ & $20-50$ & $7-20$ \\
Specific surface area BET & $\mathrm{m}^{2} / \mathrm{g}$ & $150 \pm 25$ & $90 \pm 15$ \\
Surface treatment (hydrophobization) & \multicolumn{2}{c}{ Octylsilane } \\
Density at $20^{\circ} \mathrm{C}$ & $\mathrm{g} / \mathrm{cm}^{3}$ & 2.2 & 3.2 \\
Melting point & $\mathrm{K}$ & 1973.15 & 2323.15 \\
Surface charge & \multicolumn{3}{c}{ Negative } \\
\hline
\end{tabular}

Table 3 Spray conditions.

\begin{tabular}{lcc}
\hline Parameter & Unit & Value \\
\hline Gas nature & & Air \\
Gas temperature, $T_{\text {gas }}$ & $\mathrm{K}$ & $373-773$ \\
Gas pressure, $P_{\text {gas }}$ & $\mathrm{MPa}$ & 0.5 \\
Standoff distance, $S D$ & $\mathrm{~mm}$ & 10 \\
Traverse speed, $T S$ & $\mathrm{~mm} / \mathrm{s}$ & $5,10,50$ \\
Number of passes & & $1,2,4,16$ \\
\hline
\end{tabular}

